\title{
Off-design point modelling of a 420 MW CCGT power plant integrated with an amine-based post-combustion $\mathrm{CO}_{2}$ capture and compression process
}

\author{
T. Adams ${ }^{a}$ and N. Mac Dowell ${ }^{a, b, *}$ \\ a. Centre for Process Systems Engineering, Imperial College London, South Kensington \\ Campus, London SW7 2AZ, UK \\ b. Centre for Environmental Policy, Imperial College London, South Kensington Campus, \\ London SW7 1NA, UK \\ * Corresponding author: niall@imperial.ac.uk
}

Keywords: CCGT, gas-fired power plant, $\mathrm{CO}_{2}$ capture, CCS, SAFT-VR, off-design point modelling

\section{Abstract}

The use of natural gas for power generation is becoming increasingly important in many regions in the world. Given that the combined cycle gas turbine (CCGT) power stations are lower in capital cost and carbon intensity than their coal-fired counterparts, natural gas fired power stations are considered a vital part of the transition to a low carbon economy. However, CCGTs are not themselves "low carbon" and in order to reach a carbon intensity of less than $50 \mathrm{~kg}_{\mathrm{CO}_{2}} / \mathrm{MWh}$, it will be necessary to decarbonise them via CCS, with postcombustion CCS currently regarded as being a promising technology for this application. In this study, we present a detailed model of a $420 \mathrm{MW}$ triple-pressure reheat CCGT and evaluate its technical and economic performance under full and part load conditions. We evaluate the technical performance of our CCGT model by comparison to an equivalent model implemented in Thermoflow THERMOFLEX and observe agreement of power output and efficiency to within $4.1 \%$ and the temperature profile within the HRSG within $2.9 \%$. We further integrate the CCGT with a dynamic model of an amine based CCS process, and observe a reduction in the base plant efficiency from $51.84 \%$ at full-load and $50.23 \%$ at $60 \%$ load by $8.64 \%$ points at full-load and $7.93 \%$ points at $60 \%$ load. A core conclusion of this paper is that CCGT power plants equipped with post-combustion CCS technologies are well suited to dynamic operation, as might be required in an energy system characterised by high penetrations of intermittent renewable power generation.

\section{Introduction}

The evidence base for anthropogenic $\mathrm{CO}_{2}$ emissions causing climate change is unequivocal (Intergovernmental Panel on Climate Change, 2013). $\mathrm{CO}_{2}$ emissions associated with the combustion of fossil fuels are rising, both in absolute terms and as a proportion of total anthropogenic greenhouse gases (GHGs).

However, fossil fuels are expected to play an important role in the global energy system for the foreseeable future, with natural gas possibly becoming increasingly important as part of a transition towards a low carbon energy economy (Tian, Zhang \& Wang, 2015). One key advantage of power generation via combined cycle gas turbine (CCGT) is their high efficiency relative to their coal-fired counterparts. Whilst modern CCGTs have an efficiency of approximately $51 \%$, CCGTs with an efficiency of approximately $60 \%$ are considered feasible in the near-to-medium term (Ehyaei et al., 2015). That said, whilst natural gas is a less carbon intense fuel than coal, producing in the range of $450 \mathrm{~kg}_{\mathrm{CO}_{2}} / \mathrm{MWh}$ as opposed to $\sim 800-1,000$ $\mathrm{kg}_{\mathrm{co} 2} / \mathrm{MWh}$ (Hemmer \& Klassen, 2012) it is not in itself "low carbon" - defined by the Committee on Climate Change ${ }^{1}$ to be less than $100 \mathrm{~kg}_{\mathrm{co} 2} / \mathrm{MWh}$. Indeed, it has been noted that energy systems with large portfolios of CCGT plants, without $\mathrm{CO}_{2}$ capture and storage (CCS), cannot deliver sufficient reductions in $\mathrm{CO}_{2}$ emissions in the medium to long term to meaningfully mitigate climate change (Riesz, Vithayasrichareon \& MacGill, 2015, Mac Dowell

\footnotetext{
${ }^{1}$ The Committee on Climate Change: https://www.theccc.org.uk/
} 
et al, 2010 and Duan, Fan \& Zhu, 2012). Thus, for natural gas to play a meaningful role in providing low carbon energy, CCGT power plants will need to be decarbonised via the addition of CCS technology. This is particularly important for countries like the UK where we expect to see further deployment of unabated CCGTs over the coming decade. For this reason, the development of design methodologies for the optimal retrofit of CCS technology to combined cycle gas turbine (CCGT) power plants, such as those proposed recently by Pan et al. (Pan et al., 2016) are of increasing importance.

It has been noted by, e.g., Gerbelová et al. (Gerbelová et al., 2013), that CCGT-CCS plants have an increased exposure to fuel prices relative to coal-fired power plants, CCGT-CCS plants are less costly per MWh of low carbon energy generated (Alhajaj, Mac Dowell \& Shah, 2016). Thus, CCGT-CCS plants can be deployed in response to a relatively low $\mathrm{CO}_{2}$ price (Nogueira et al., 2014 and Johnsson, Odenberger \& Göransson, 2014 and Gerbelová et al., 2013). Whilst novel technologies, such as molten carbonate fuel cells and calcium looping processes (Cormos \& Simon, 2013), have been proposed for decarbonising CCGT power plants (Campanari et al., 2014), the vast majority of current academic literature focuses on the utilisation of post-combustion amine scrubbing as the technology of choice for this purpose (Spence, Horan \& Tucker, 2014 and Ceccarelli et al., 2014). In this context, an aqueous $30 \mathrm{wt} \%$ solution of monoethanolamine (MEA) is still considered the benchmark solvent for the majority of academic studies (Boot-Handford et al., 2014).

Over the course of the $21^{\text {st }}$ century, the energy system is expected to integrate increasing quantities of intermittent renewable energy (Brouwer et al., 2015 and Mac Dowell \& Staffell, 2016). In the absence of suitable solutions for grid scale, inter-seasonal energy storage, the flexible and dispatchable nature of fossil-based power generation will become increasingly valued (Mac Dowell \& Staffell, 2016, Rezazadeh et al., 2015, Flø, Kvamsdal \& Hillestad, 2016 and Turconi et al., 2014). Thus, decarbonised CCGTs will be required to operate in a flexible load following manner - providing peaking capacity in addition to their current role as midmerit provider in the energy system. This has been noted in a number of previous contributions to this literature, such as that of Ceccarelli et al. (Ceccarelli et al., 2014) wherein a study detailing the likely start-up/shut-down behaviour of a CCGT-CCS plant was presented. For this reason, models that describe the dynamic and off-design point of these systems will be of increasing value.

As has been noted by Brouwer et al. (Brouwer et al., 2015 and Mac Dowell \& Staffell, 2016), increased penetration of intermittent renewable power will tend to decrease the efficiency of thermal power plants, and will likely exert an upward influence on wholesale electricity prices. However, it is also important that the potential role of CCS in the provision of baseload power generation should not be dismissed, and in regions with limited availability of renewable energy resources, CCS can play a role in the provision of baseload power (Johnsson, Odenberger \& Göransson, 2014). Importantly, as has been noted by Kang et al. (Kang, Brandt \& Durlofsky, 2015) the likely operating mode of the CCGT-CCS plant (base load or flexible operation) will significantly influence the profitability of the plant.

Building on this point and in light of the increasing role that natural gas is playing in the global energy system, Middleton and Eccles (Middleton \& Eccles, 2013) presented an insightful analysis highlighting the link between variations in generating patterns of CCGT-CCS plants and their $\mathrm{CO}_{2}$ emissions. They found that the prices required to incentivise the capture of the $\mathrm{CO}_{2}$ was a function of the generating patterns required of the plants - in other words, a single $\mathrm{CO}_{2}$ price (or tax) may not be sufficient to deliver low carbon electricity. For this reason, advanced operating strategies for operation under load-following conditions are important to maximise profitability (Mac Dowell \& Shah, 2014 and Mac Dowell \& Shah, 2015). However, a recent study by Benato et al. (Benato et al., 2015), highlighted the fact that increased frequency of power plant start-up/shut-down cycles and ramping of the power plant can result in a reduction in the operational lifetime of the power plant owing to thermo-mechanical fatigue, creep and corrosion. This serves to underscore the requirement to develop detailed models describing the behaviour of decarbonised CCGT power plants operating at a range of off-design point and part-load operating conditions.

One of the key challenges in capturing $\mathrm{CO}_{2}$ from the exhaust gas of a CCGT is the relatively dilute nature of the exhaust gas of a CCGT relative to a coal-fired power plant. Where a coalfired power plant will typically have an exhaust gas with a $\mathrm{CO}_{2}$ concentration of $10-15 \mathrm{~mol} \%$, 
a CCGT will have an exhaust gas with a $\mathrm{CO}_{2}$ concentration in the range of $3-5 \mathrm{~mol} \%$. Similarly, the volumetric flow of exhaust gas per MWh from a CCGT is greater than the corresponding flow from a coal-fired power station, typically by a factor of $\sim 1.4-1.6$ (Sipöcz et al., 2010). An unavoidable consequence of this is that the minimum thermodynamic work required to perform this separation will inevitably increase from $\sim 7 \mathrm{~kJ} / \mathrm{mol}_{\mathrm{CO} 2}$ in the case of a coal plant to $\sim 10 \mathrm{~kJ} / \mathrm{mol}_{\mathrm{CO} 2}$ in the case of the CCGT. A further challenge associated with the application of amine-based post-combustion $\mathrm{CO}_{2}$ capture to CCGTs is the relatively high $\mathrm{O}_{2}$ content in the exhaust gas. Where in a coal-fired power plant, the exhaust gas will typically contain $4-6 \mathrm{~mol} \% \mathrm{O}_{2}$, the exhaust gas of a CCGT will potentially contain up to $10-12$ mol\%. This is a problem, as $\mathrm{O}_{2}$ is well known to degrade alkanolamines (Mertens et al., 2013 and Lepaumier, Picq and Carrette, 2009), thus adding to process operating cost. Thus, exhaust gas recirculation (or recycling), known as EGR, is considered as a useful method to address these challenges (ElKady et al., 2009) and reduce process costs (Sipöcz \& Tobiesen, 2012). EGR involves the recycling of a portion of the exhaust gas exiting the heat recovery steam generator (HRSG) to the compressor of the gas turbine (Herraiz et al., 2015). The concept of EGR has previously been applied to gas compressors (Loud \& Slaterpryce, 1991), and indeed may well be applied to compressors operating as part of a CCS process in the event of part load operation of the power plant leading to a substantially reduced flow of $\mathrm{CO}_{2}$ from the power plant. Importantly, it has been observed that the application of EGR to a CCGR would result in negligible variation in turbine performance (Canepa et al., 2013 and Jonshagen, Sipöcz \& Genrup, 2010), implying that this could be readily incorporated as part of a CCS-retrofit operation.

In this study, we present a detailed mathematical model of a $420 \mathrm{MW}$ triple-pressure combined cycle gas turbine (CCGT) power plant integrated with a post-combustion $\mathrm{CO}_{2}$ capture process. We evaluate the performance of the CCGT with exhaust gas recycle (EGR) and CCS under range off-design point operational modes. All modelling work in this study was performed using the gPROMS platform.

The remainder of this paper is laid out as follows. First, mathematical descriptions of the individual sub-models, which comprise the CCGT and compression system, are presented. Then, the model validation process is described and the adequacy of our model across a range of operating points is quantified. We go on to describe the integration of the CCGT, $\mathrm{CO}_{2}$ capture and compression system, and validate the technical and economic performance of our model by comparison with the current literature. Finally, we conclude a perspective on the implications of this work on the role that CCS-equipped CCGTs may play in the future energy system and some thoughts for future work.

\section{Nomenclature and Abbreviations}

$\begin{array}{ll}A & \text { Heat transfer area }(\mathrm{m}) \\ C & \text { Heat capacity flow rate }\left(\mathrm{kW} \mathrm{K}^{-1}\right) \\ C^{*} & \text { Heat capacity flow rate ratio } \\ C_{\max } & \text { Maximum heat capacity flow rate }\left(\mathrm{kW} \mathrm{K} \text { K-1 }^{-1}\right) \\ C_{\min } & \text { Minimum heat capacity flow rate }\left(\mathrm{kW} \mathrm{K}^{-1}\right) \\ c_{p} & \text { Specific heat capacity }\left(\mathrm{kJ} \mathrm{kmol}^{-1} \mathrm{~K}^{-1}\right) \\ \mathrm{CAP} & \text { Capital cost of the project } \\ \text { CCGT } & \text { Combined cycle gas turbine } \\ \mathrm{CF} & \text { Capacity factor (average plant load) } \\ \mathrm{CRF} & \text { Capital recovery factor } \\ \mathrm{EGR} & \text { Exhaust gas recycle } \\ f_{\mathrm{CO} 2} & \text { Fraction of the } \mathrm{CO}_{2} \text { in the flue gas that is captured } \\ \mathrm{FGC} & \text { Fixed geometry compressor } \\ g_{i, j} & \text { Value of variable } i \text { at load } j \\ h & \left.\text { Specific enthalpy (kJ kmol }{ }^{-1}\right) \\ \mathrm{HP} & \text { High pressure } \\ i & \text { Interest rate }(\%) \\ \text { IP } & \text { Intermediate pressure } \\ \text { LCOE } & \text { Levelised cost of electricity } \\ \text { LF } & \text { Load factor } \\ \text { LHV } & \text { Lower heating value } \\ \text { LP } & \text { Low pressure }\end{array}$




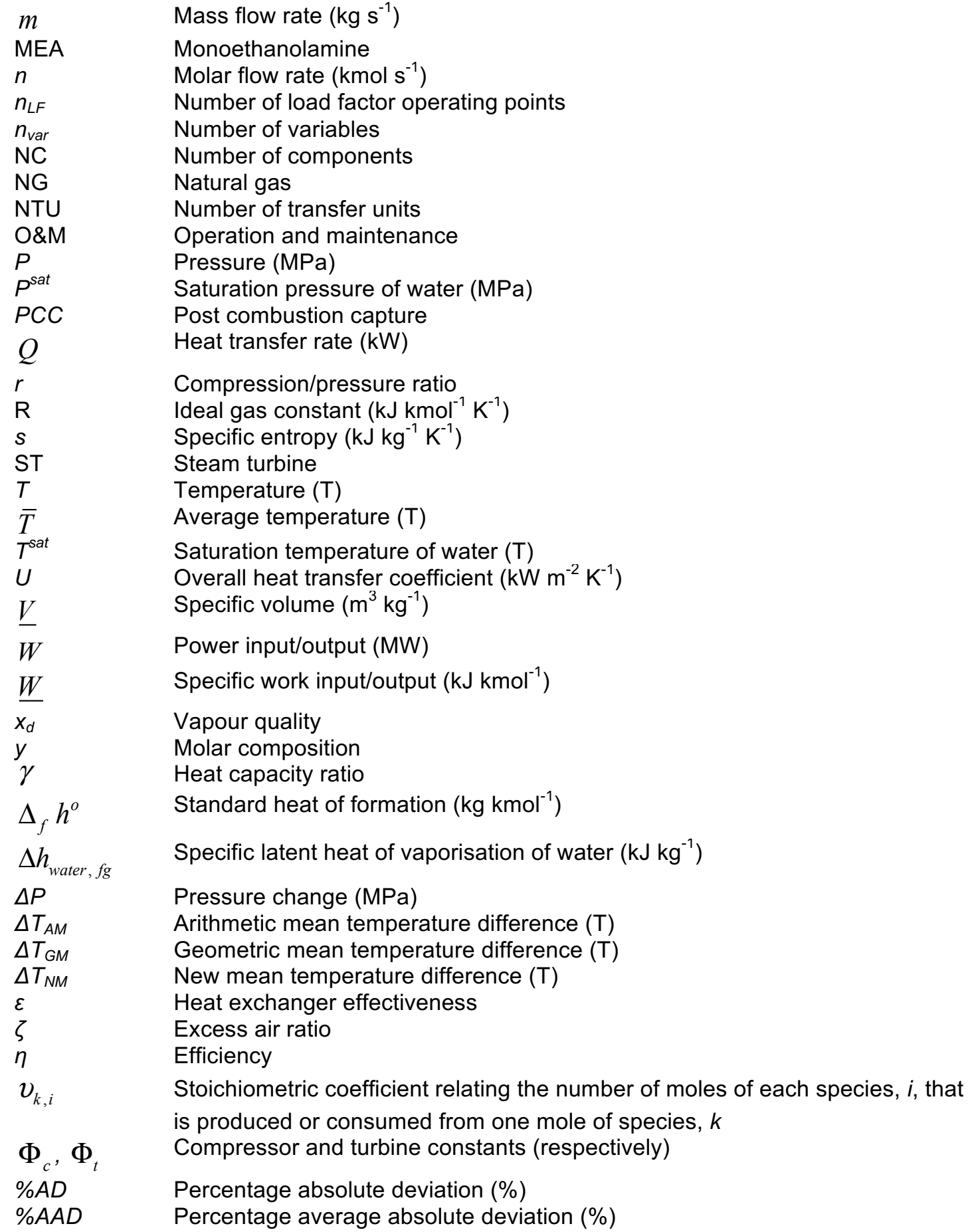

Mass flow rate $\left(\mathrm{kg} \mathrm{s}^{-1}\right)$

Monoethanolamine

Molar flow rate $\left(\mathrm{kmol} \mathrm{s}^{-1}\right)$

Number of load factor operating points

Number of variables

Number of components

Natural gas

Number of transfer units

Operation and maintenance

Pressure (MPa)

Saturation pressure of water (MPa)

Post combustion capture

Heat transfer rate $(\mathrm{kW})$

Compression/pressure ratio

Ideal gas constant $\left(\mathrm{kJ} \mathrm{kmol}^{-1} \mathrm{~K}^{-1}\right)$

Specific entropy $\left(\mathrm{kJ} \mathrm{kg}^{-1} \mathrm{~K}^{-1}\right)$

Steam turbine

Temperature $(T)$

Average temperature $(T)$

Saturation temperature of water $(T)$

Overall heat transfer coefficient $\left(\mathrm{kW} \mathrm{m}{ }^{-2} \mathrm{~K}^{-1}\right)$

Specific volume $\left(\mathrm{m}^{3} \mathrm{~kg}^{-1}\right)$

Power input/output (MW)

Specific work input/output (kJ kmol $\left.{ }^{-1}\right)$

Vapour quality

Molar composition

Heat capacity ratio

Standard heat of formation $\left(\mathrm{kg} \mathrm{kmol}^{-1}\right)$

Specific latent heat of vaporisation of water $\left(\mathrm{kJ} \mathrm{kg}^{-1}\right)$

Pressure change (MPa)

Arithmetic mean temperature difference $(T)$

Geometric mean temperature difference $(T)$

New mean temperature difference $(T)$

Heat exchanger effectiveness

Excess air ratio

Efficiency

Stoichiometric coefficient relating the number of moles of each species, $i$, that is produced or consumed from one mole of species, $k$

Compressor and turbine constants (respectively)

\section{Subscripts}

$\begin{array}{ll}c & \text { Compressor } \\ c a l c & \text { As calculated from the gPROMS model } \\ c w & \text { Cooling water } \\ f g & \text { Flue gas } \\ \text { isen } & \text { Isentropic } \\ \text { mech } & \text { Mechanical } \\ s s & \text { Steady state } \\ t & \text { Turbine } \\ T F & \text { As obtained from the Thermoflow THERMOFLEX model } \\ \text { water,f } & \text { Water in the liquid phase } \\ \text { water,fg } & \text { Water in its liquid-gas transition phase } \\ \text { water,g } & \text { Water in the gaseous phase }\end{array}$




\section{Superscripts}

$\begin{array}{ll}\text { design } & \text { Denotes values calculated at full-load operation of the CCGT } \\ \text { ideal } & \text { As calculated under ideal isentropic conditions } \\ \text { in } & \text { Denotes an inlet stream to a process unit } \\ n & \text { Plant lifetime } \\ \text { out } & \text { Denotes an outlet stream from a process unit } \\ \alpha, \beta & \text { Exponential constants } \\ \varepsilon-N T U & \text { As calculated by the } \varepsilon \text {-NTU method }\end{array}$

\section{Model Presentation}

The physical properties package Multiflash 4.1 was used to predict the physical properties of the air, flue gas, water, steam and fuel streams in the CCGT and compression train models that were created. The SAFT-VR equation-of-state (Gil-Villegas et al., 1997 and Galindo, Davies \& Jackson, 1998) was used to describe the thermophysical properties of the MEAsolvent used in the PCC plant model using the approach described in our previous work (Mac Dowell et al., 2009, Mac Dowell et al., 2010, Mac Dowell et al., 2012 and Rodriguez et al., 2012).

\subsection{CCGT Power Plant}

A detailed steady-state model of a $420 \mathrm{MW}$ triple-pressure reheat gas-fired CCGT was created based on the parameters and process configuration of a Thermoflow THERMOFLEX model of a triple-pressure reheat CCGT with a state-of-the-art Siemens SGT5-4000F gas turbine. A process flow diagram of the standalone CCGT model is shown in Figure 1.

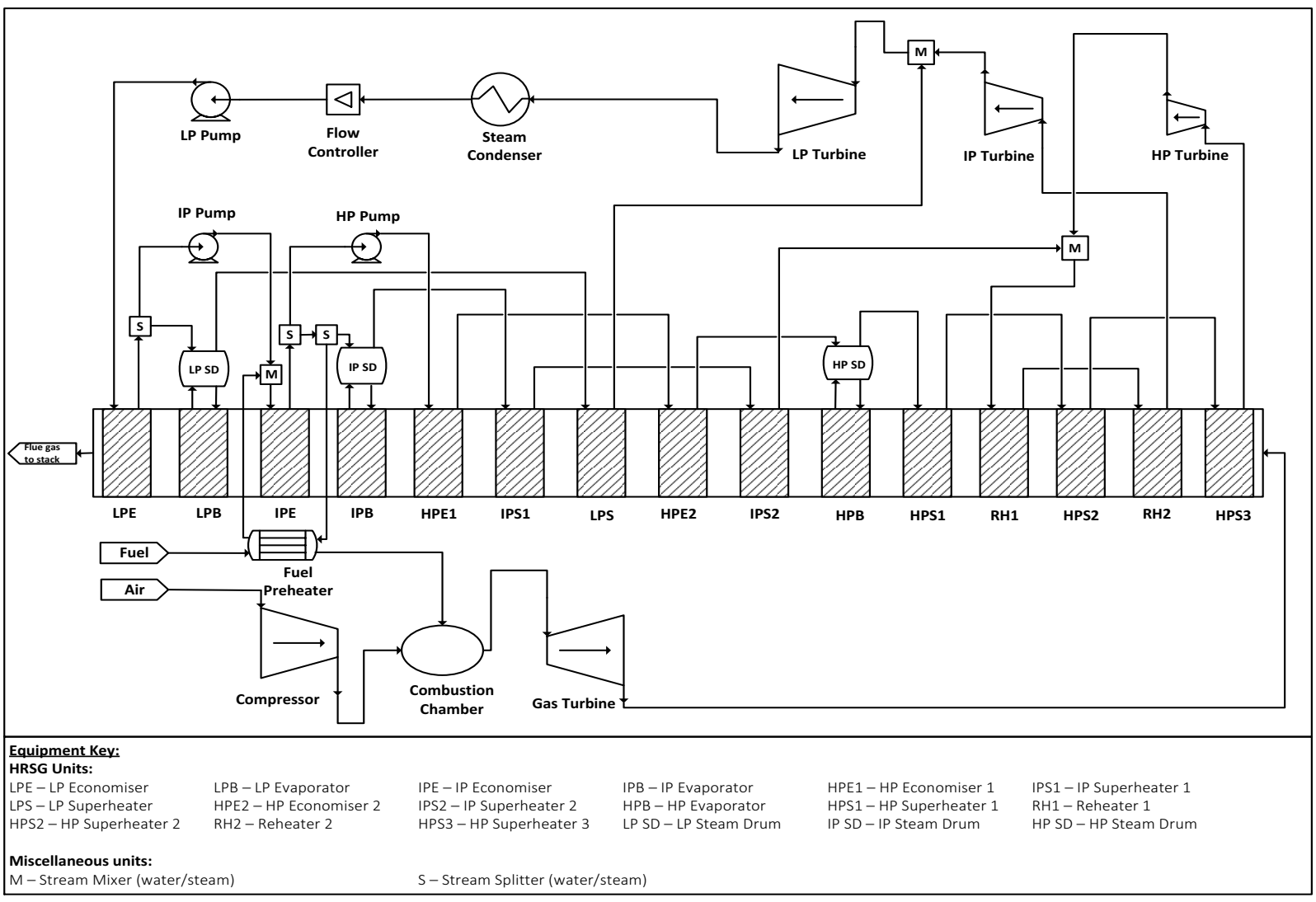

Figure 1: Process flow diagram of the standalone CCGT power plant model

Our model has two operational modes: calibration and operation. The model of the CCGT plant was first simulated in calibration mode in order to size the units of the plant so that the 
outputs of the gPROMS model could be calibrated against those of the THERMOFLEX model. This is, in effect, a model parameterisation step. This allows us to assign values to parameters such as compressor efficiency or accurately size heat exchangers. Subsequently, the operation mode model of the CCGT was simulated in which the sizes of the process units were assigned to the values determined in the calibration mode model and the unit models were modified in order to predict their behaviour at off-design conditions.

\subsubsection{Compressor}

\subsubsection{Calibration Mode}

A compressor model was used to calculate the unit's power requirement and discharge temperature. The model assumes that the air behaves as an ideal gas, the compression is reversible and adiabatic and there is a constant mass flow rate through the unit. The power requirement of the compressor was calculated using the following equations (Pritchard, 2011):

$$
\begin{aligned}
& W_{\text {in }}=\frac{n_{\text {air }}^{\text {in }} \underline{W}_{\text {in }}}{1000} \\
& \underline{W}_{\text {in }}=\frac{\underline{W}_{\text {in, ideal }}}{\eta_{c}} \\
& \underline{W}_{\text {in,ideal }}=\left(\frac{\gamma}{\gamma-1}\right) P_{\text {air }}^{\text {in }} \underline{V}_{\text {air }}^{\text {in }}\left[\left(\frac{P_{\text {air }}^{\text {out }}}{P_{\text {air }}^{\text {in }}}\right)^{\frac{\gamma-1}{\gamma}}-1\right]
\end{aligned}
$$

Where the specific volume of the inlet air is:

$$
\underline{V}_{\text {air }}^{\text {in }}=\frac{R T_{\text {air }}^{\text {in }}}{P_{\text {air }}^{\text {in }}}
$$

The temperature of the outlet stream from the compressor is (Horlock, 2003):

$$
T_{\text {air }}^{\text {out }}=\frac{T_{\text {air }}^{\text {in }}}{\eta_{c}}\left[\left(\frac{P_{\text {aut }}^{\text {out }}}{P_{\text {air }}^{\text {in }}}\right)^{\frac{\gamma-1}{\gamma}}-1\right]+T_{\text {air }}^{\text {in }}
$$

The isentropic efficiency of the compressor, $\eta_{c}$, was assigned the value of 0.88 .

\subsubsection{Operation Mode}

In operation mode, the outlet pressure is no longer assigned. Instead, equation 6 (Moller, Genrup \& Assadi, 2007) is used to predict the outlet pressure of a fixed geometry compressor (FGC) at off-design conditions. We first calculate the value of the compressor constant, $\Phi_{c}$, by substituting in the values of the other parameters as obtained from the simulation of the compressor in calibration mode.

$$
P_{\text {air }}^{\text {out } F G C}=\frac{\Phi_{c}\left(n_{\text {air }}^{\text {in }} \sqrt{T_{\text {air }}^{i n}}\right)^{2}}{P_{\text {air }}^{\text {in }}}+P_{\text {air }}^{\text {in }}
$$

In practice the air compressor will have variable inlet guide vanes (VIGVs) that allow for more efficient operation at part loads. The following empirical correlation is therefore used to correct the outlet pressures predicted by the above law to the outlet pressures from the compressor in the Siemens SGT5-4000F gas turbine in the THERMOFLEX model: 


$$
P_{\text {air }}^{\text {out }}=P_{\text {air }}^{\text {out }, F G C} \times\left(\left(-0.36 \times n_{\text {air }}^{\text {in }}\right)+1.8316\right)
$$

Equations 1-5 are used again to determine the work requirements and the temperature of the outlet stream from the compressor. It was observed from THERMOFLEX simulations that the value of $\eta_{c}$ does not vary by more than $4 \%$ between $40-100 \%$ load. Therefore, a constant value of 0.86 was therefore assumed.

\subsubsection{Combustion Chamber}

Whilst typical "natural gas" is not composed of 100\% methane (Mansouri et al. 2012), and could potentially contain as little as $89 \% \mathrm{CH}_{4}$, a typical value is approximately $97 \%$. Therefore, the following reactions were included in our model:

$$
\begin{aligned}
& \mathrm{CH}_{4}+2 \mathrm{O}_{2} \rightarrow \mathrm{CO}_{2}+2 \mathrm{H}_{2} \mathrm{O} \\
& \mathrm{C}_{2} \mathrm{H}_{6}+\frac{7}{2} \mathrm{O}_{2} \rightarrow 2 \mathrm{CO}_{2}+3 \mathrm{H}_{2} \mathrm{O} \\
& \mathrm{C}_{3} \mathrm{H}_{8}+5 \mathrm{O}_{2} \rightarrow 3 \mathrm{CO}_{2}+4 \mathrm{H}_{2} \mathrm{O} \\
& \mathrm{H}_{2}+\frac{1}{2} \mathrm{O}_{2} \rightarrow \mathrm{H}_{2} \mathrm{O} \\
& \mathrm{H}_{2} \mathrm{~S}+\frac{3}{2} \mathrm{O}_{2} \rightarrow \mathrm{H}_{2} \mathrm{O}+\mathrm{SO}_{2} \\
& \mathrm{CO}+\frac{1}{2} \mathrm{O}_{2} \rightarrow \mathrm{CO}_{2} \\
& \mathrm{NH}_{3}+\frac{3}{4} \mathrm{O}_{2} \rightarrow \frac{1}{2} \mathrm{~N}_{2}+\frac{3}{2} \mathrm{H}_{2} \mathrm{O}
\end{aligned}
$$

The following matrix of coefficients, $v_{k, i}$, relates the number of moles of each species, $i$, that is produced or consumed following the introduction of one mole of species, $k$, in the fuel to the combustion chamber. The fuel species, $k$, are either inert or undergo complete combustion. 


\begin{tabular}{|c|c|c|c|c|c|}
\hline & $\mathrm{O}_{2}$ & $\mathrm{~N}_{2}$ & $\mathrm{CO}_{2}$ & $\mathrm{H}_{2} \mathrm{O}$ & $\mathrm{SO}_{2}$ \\
\hline$v_{O_{2}, i}=$ & {$[1$,} & 0 & 0 & 0 & 0 \\
\hline$v_{N_{2}, i}=$ & {$[0$} & 1, & 0 & 0 & 0 \\
\hline$v_{C O_{2}, i}=$ & {$[0$} & 0 & 1, & 0 & 0 \\
\hline$v_{C_{4}, i}=$ & {$[-2$,} & 0 & 1, & 2 & 0 \\
\hline$v_{C_{2} H_{6}, i}=$ & {$\left[-\frac{7}{2}\right.$,} & 0 & 2 & 3 & 0 \\
\hline$v_{C_{3} H_{8}, i}=$ & {$[-5$} & 0 & 3 & 4 & 0 \\
\hline$v_{H_{2}, i}=$ & {$\left[-\frac{1}{2}\right.$,} & 0 & 0 & 1 & 0 \\
\hline$v_{H_{2} S, i}=$ & {$\left[-\frac{3}{2}\right.$,} & 0 & 0 & 1, & 1, \\
\hline$v_{C O, i}=$ & {$\left[-\frac{1}{2}\right.$,} & 0 & 1, & 0 & 0 \\
\hline$v_{N H_{2}, i}=$ & {$\left[-\frac{3}{4}\right.$,} & $\frac{1}{2}$, & 0 & $\frac{3}{2}$ & 0 \\
\hline
\end{tabular}

Noting that our model has the flexibility to real blends, for the purposes of this study, we assume that the fuel gas is entirely composed of $\mathrm{CH}_{4}$, and that the fuel is completely combusted at all load factors.

The molar flow rate of each species in the flue gas, $n_{f g, i}^{\text {out }}$, is calculated by mass balance:

$$
n_{f g, i}^{\text {out }}=n_{\text {air }}^{\text {in }} y_{\text {air }, i}^{\text {in }}+n_{\text {fuel }}^{\text {in }} \sum_{k=1}^{N C_{\text {fuel }}} y_{\text {fuel }, k}^{\text {in }} v_{k, i} .
$$

The total molar flow rate of the flue gas stream is given by:

$$
n_{f g}^{o u t}=\sum_{i=1}^{N C_{f g}} n_{f g, i}^{o u t}
$$

The excess air ratio is calculated by comparing the number of moles of $\mathrm{O}_{2}$ present in the air supplied to the net number of moles of $\mathrm{O}_{2}$ required for complete combustion of the fuel:

$$
\zeta_{\text {air }}=\frac{n_{\text {air }}^{\text {in }} y_{\text {air }, O_{2}}^{\text {in }}}{-n_{\text {fuel }}^{\text {in }} \sum_{k=1}^{N C_{\text {fuel }}} y_{\text {fuel }, k}^{\text {in }} v_{k, O_{2}}}
$$

The temperature of the flue gas leaving the combustion chamber is calculated via an energy balance on the streams entering and leaving the unit, with the combustion process assumed to be adiabatic: 


$$
\begin{gathered}
n_{f g}^{\text {out }}\left[\sum_{i=1}^{N C_{f g}} y_{f g, i}^{\text {out }} \Delta_{f} h_{f g, i}^{o}+c_{p, f g}\left(T_{f g}^{\text {out }}-T^{o}\right)\right]=n_{\text {air }}^{\text {in }}\left[\sum_{i=1}^{N C_{\text {air }}} y_{\text {air }, i}^{\text {in }} \Delta_{f} h_{\text {air }, i}^{o}+c_{p, \text { air }}\left(T_{\text {air }}^{\text {in }}-T^{o}\right)\right] \\
+n_{\text {fuel }}^{\text {in }}\left[\sum_{k=1}^{N C_{\text {fuel }}} y_{\text {fuel }, k}^{\text {in }} \Delta_{f} h_{\text {fuel }, k}^{o}+c_{p, \text { fuel }}\left(T_{\text {fuel }}^{\text {in }}-T^{o}\right)\right]
\end{gathered}
$$

The standard heats of formation of air, fuel and flue gas components were taken from the NIST Webbook database and from (Perry, 1997). For completeness, both heats of formation at $25^{\circ} \mathrm{C}$ and lower heating values, LHV, of each component are reported in Table 1.

There will be a pressure drop in the air stream across the combustion chamber of $3 \%$ of the compressor delivery pressure at all loads (Horlock, 2003):

$$
\begin{aligned}
& P_{f g}^{\text {out }}=P_{\text {air }}^{\text {in }} \times\left(1-\Delta P_{\text {loss }}\right) \\
& \Delta P_{\text {loss }}=0.03
\end{aligned}
$$

\begin{tabular}{|c|c|c|}
\hline Species & $\begin{array}{l}\text { Standard heat of formation, } \Delta_{f} \\
h^{\circ}\left(\mathrm{kJ} \mathrm{kmol}^{-1}\right)\end{array}$ & $\begin{array}{l}\text { Lower heating value, LHV (MJ } \\
\qquad \mathrm{kmol}^{-1} \text { ) }\end{array}$ \\
\hline $\mathrm{O}_{2}$ & 0 & 0 \\
\hline $\mathrm{N}_{2}$ & 0 & 0 \\
\hline $\mathrm{CO}_{2}$ & $-393,510$ & 0 \\
\hline $\mathrm{H}_{2} \mathrm{O}$ & $-241,826$ & 0 \\
\hline $\mathrm{SO}_{2}$ & $-296,810$ & 0 \\
\hline $\mathrm{Ar}$ & 0 & 0 \\
\hline $\mathrm{CH}_{4}$ & $-74,870$ & 800.992 \\
\hline $\mathrm{C}_{2} \mathrm{H}_{6}$ & $-84,000$ & $1,425.96$ \\
\hline $\mathrm{C}_{3} \mathrm{H}_{8}$ & $-104,700$ & $2,041.6$ \\
\hline $\mathrm{H}_{2}$ & 0 & 240.136 \\
\hline $\mathrm{H}_{2} \mathrm{~S}$ & $-20,600$ & No data \\
\hline $\mathrm{CO}$ & $-110,530$ & 283.164 \\
\hline $\mathrm{NH}_{3}$ & $-45,940$ & No data \\
\hline
\end{tabular}

Table 1: Standard heats of formation and lower heating values of the constituent species of the air, fuel and flue gas components

\subsubsection{Gas Turbine}

\subsubsection{Calibration Mode}

The turbine model is based on the same thermodynamic principles and assumptions that were used to model the compressor in Section 3.1.1, and the same approach was taken during calibration and operation modes. The power output of the turbine is calculated using the following equations (Pritchard, 2011):

$$
\begin{aligned}
W_{\text {out }} & =\frac{n_{f g}^{\text {in }} \underline{W}_{\text {out }}}{1000} \\
\underline{W}_{\text {out }} & =\eta_{t} \underline{W}_{\text {out }, \text { ideal }}
\end{aligned}
$$




$$
\underline{W}_{\text {out }, \text { ideal }}=-\left(\frac{\gamma}{\gamma-1}\right) P_{f g}^{\text {in }} V_{f g}^{\text {in }}\left[\left(\frac{P_{f g}^{\text {out }}}{P_{f g}^{\text {in }}}\right)^{\frac{\gamma-1}{\gamma}}-1\right]
$$

Where the specific volume of the inlet flue gas is:

$$
\underline{V}_{f g}^{i n}=\frac{R T_{f g}^{i n}}{P_{f g}^{i n}}
$$

The temperature of the outlet stream from the gas turbine is (Horlock, 2003):

$$
T_{f g}^{o u t}=T_{f g}^{i n}-\eta_{t} T_{f g}^{i n}\left[1-\left(\frac{P_{f g}^{\text {out }}}{P_{f g}^{i n}}\right)^{\frac{\gamma-1}{\gamma}}\right]
$$

The isentropic efficiency of the gas turbine, $\eta_{t}$, was assigned a value of 0.9 .

\subsubsection{Operation Mode}

In the operation mode gas turbine model, the outlet pressure of the turbine is related to the inlet conditions through Stodola's law as shown in equation 26 . The value of the turbine constant, $\Phi_{t}$, must be calculated and this is done in the same manner in which $C_{c}$ was calculated in section 3.1.1.

$$
\left(P_{f g}^{o u t}\right)^{2}=P_{f g}^{i n} \times\left(1-\left(\frac{n_{f g}^{i n} \sqrt{T_{f g}^{i n}}}{P_{f g}^{i n} \Phi_{t}}\right)^{2}\right)
$$

The outlet pressure predicted by Stodola's law is very sensitive to changes of the temperature, pressure and flow rate of the inlet flue gas to the turbine as indicated by the squared term in the right-hand side of equation 26. For this reason, Stodola's law may predict negative outlet conditions depending on how the inlet conditions are varied relative to each other. Therefore, the outlet pressure of the turbine, $P_{f g}^{\text {out }}$, was set to a constant value of $0.1035 \mathrm{MPa}$ at all loads and the gas turbine model therefore sets the flow rate of air into the compressor (which then determines the compressor discharge pressure and combustion chamber outlet pressure) that will produce this value of $P_{f g}^{\text {out }}$.

Equations 21-25 are used again to determine the work output and the temperature of the outlet stream from the turbine. The THERMOFLEX model showed that the value of $\eta_{t}$ does not vary by more than $2 \%$ between $40-100 \%$ so that a constant value of 0.89 could be assumed.

\subsubsection{HRSG (Flue Gas Side)}

The heat recovery steam generator (HRSG) is a distributed model with 15 discretisation points where flue gas flows down a series of economiser, evaporator and superheater tube sections. There will be a slight pressure drop as the flue gas flows through the HRSG and the flue gas exits at approximately $0.1033 \mathrm{MPa}$. A simple linear correlation was implemented to produce a flue gas with this outlet pressure:

$$
P_{f g}^{\text {out, stage } i}=P_{f g}^{i n, \text { stage } i}-\frac{P_{f g}^{\text {in, stage } 1}-0.1033}{\text { number of stages }(15)}
$$


The flue gas exhaust temperature is calculated by energy balance that considers the quantity of heat transferred from the gas to the steam cycle along the HRSG. The system is assumed to be adiabatic with perfect radial distribution of heat.

$$
n_{f g}^{\text {in }} h_{f g}^{\text {in }}=n_{f g}^{\text {out }} h_{f g}^{\text {out }}+Q
$$

\subsubsection{Economiser}

\subsubsection{Calibration Mode}

A calibration mode economiser model was created to size the heat transfer area of every economiser section in the HRSG. The model assumes counter-current heat exchange, no radial temperature profiles in the tubes, no pressure drop along the water side and the heat capacity of the water is evaluated at the average temperature along the economiser section. The outlet water temperatures in each economiser section are using the THERMOFLEX model at full load and heat exchange areas sized accordingly. Economiser sections that send water directly to steam drums will be set to produce outlet water streams with an approach temperature of $5 \mathrm{~K}$ (i.e. $5 \mathrm{~K}$ below the saturation temperature at the operating pressure of the economiser section). The heat transfer rate required in each economiser section is therefore calculated as:

$$
Q=m_{\text {water }}^{\text {in }} c_{p, \text { water }}\left(T_{\text {water }}^{\text {out }}-T_{\text {water }}^{\text {in }}\right)
$$

The heat transfer area of each economiser can then be calculated from (Paterson, 1984):

$$
\begin{aligned}
& Q=U A \Delta T_{N M} \\
& \Delta T_{N M}=\frac{2}{3} \Delta T_{G M}+\frac{1}{3} \Delta T_{A M} \\
& \left(\Delta T_{G M}\right)^{2}=\left(T_{f g}^{\text {in }}-T_{\text {water }}^{\text {out }}\right) \times\left(T_{f g}^{\text {out }}-T_{\text {water }}^{\text {in }}\right) \\
& 2 \Delta T_{A M}=\left(T_{f g}^{\text {in }}-T_{\text {water }}^{\text {out }}\right)+\left(T_{f g}^{\text {out }}-T_{\text {water }}^{\text {in }}\right)
\end{aligned}
$$

The value of the overall heat transfer coefficient, $U$, was taken as $0.375 \mathrm{~kW} \mathrm{~m}^{-2} \mathrm{~K}^{-1}$ (Sinnott, 2005).

\subsubsection{Operation Mode}

Once the heat transfer areas of each economiser section have been set, the $\varepsilon$-NTU method can be used be used to predict the outlet temperatures of the water and flue gas streams. The rate of heat transfer in each economiser section is given by the following equations (Shah, 2003):

$$
\begin{aligned}
& Q=\varepsilon C_{\min }\left(T_{f g}^{\text {in }}-T_{\text {water }}^{\text {in }}\right) \\
& \mathcal{E}=\frac{1-\exp \left[-N T U\left(1-C^{*}\right)\right]}{1-C^{*} \exp \left[1-C^{*}\right]} \\
& N T U=\frac{U A}{C_{\min }} \\
& C^{*}=\frac{C_{\text {min }}}{C_{\max }}
\end{aligned}
$$


Where the heat capacity flow rates of the water and flue streams are given as:

$$
\begin{aligned}
& C_{\text {water }}=m_{\text {water }}^{\text {in }} c_{p, \text { water }} \\
& C_{f g}=n_{f g}^{i n} c_{p, f g}
\end{aligned}
$$

The higher and lower of these two heat capacity flow rates can be identified as:

$$
\begin{aligned}
& C_{\text {max }}=\max \left(C_{\text {water }}, C_{f g}\right) \\
& C_{\text {min }}=\min \left(C_{\text {water }}, C_{f g}\right)
\end{aligned}
$$

The value of the overall heat transfer coefficient will change during off-design operation. In 1995, Dechamps and co-workers (Dechamps, Pirard \& Mathieu, 1995) proposed a simple formula for relating the overall heat transfer coefficient in the HRSG sections to the off-design gas-side properties:

$$
U=U^{\text {design }}\left(\frac{n_{f g}^{\text {in }}}{n_{f g}^{\text {in, design }}}\right)^{\alpha}\left(\frac{\bar{T}}{\bar{T}^{\text {design }}}\right)^{\beta}
$$

This is used in its simplified form, as shown in equation 43 , as the average flue gas temperatures across each economiser section do not change drastically from their respective full-load values, thus the second quotient in equation 42 can be approximated as unity, reducing the numerical complexity in solving this model.

$$
U=U^{\text {design }}\left(\frac{n_{f g}^{i n}}{n_{f g}^{\text {in, design }}}\right)^{\alpha}
$$

The value of the exponential term $\alpha$ was assigned a value of $\alpha=0.7$.

The outlet temperature of the flue gas is given as:

$$
T_{f g}^{o u t}=T_{f g}^{i n}-\frac{Q}{C_{f g}}
$$

The temperature of the outlet water stream as predicted by the $\varepsilon$-NTU equations is:

$$
T_{\text {water }}^{\text {out }, \varepsilon-N T U}=T_{\text {water }}^{\text {in }}+\frac{Q}{C_{\text {water }}}
$$

The economiser sections normally operate with water exit temperatures very close to the saturation temperature of water and the $\varepsilon$-NTU equations do not account for the possibility that partial evaporation may occur and the temperature of the outlet water predicted by equation $45, T_{\text {water }}^{\text {out } \varepsilon-N T U}$, may be higher than the saturation temperature, $T_{\text {water }}^{\text {sat }}$. Once the saturation temperature is reached, any additional heat transfer will go towards the latent heating of the water and no further temperature rise will occur until the full latent heat of vaporisation of the water is delivered. This concept is illustrated Figure 2: 


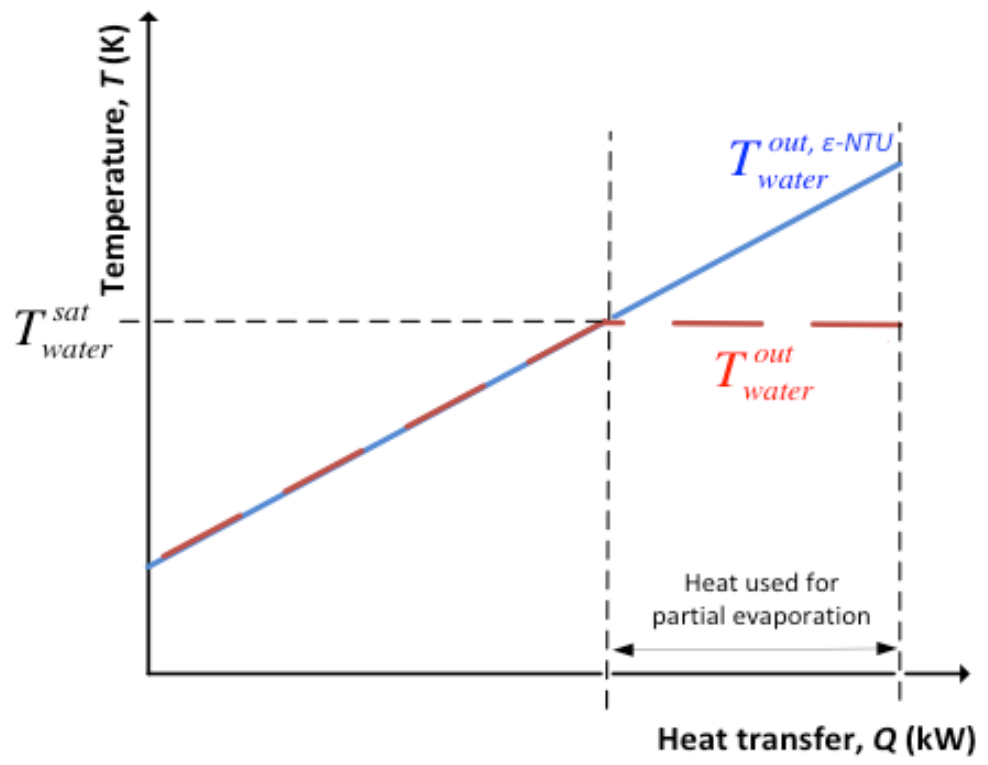

Figure 2: Temperature profile graph illustrating the difference between the actual economiser outlet temperature and the temperature predicted by the $\varepsilon$-NTU method

The actual temperature, $T_{\text {water }}^{\text {out }}$, and vapour quality, $x_{d \text {, water }}^{\text {out }}$, of the outlet water is therefore determined by:

$$
\begin{aligned}
& \text { If } T_{\text {water }}^{\text {out },-N T U} \leq T_{\text {water }}^{\text {sat }} \text { then } \\
& T_{\text {water }}^{\text {out }}=T_{\text {water }}^{\text {out },-N T U} \\
& x_{d, \text { water }}^{\text {out }}=0
\end{aligned}
$$

\section{ELSE}

$$
\begin{aligned}
& T_{\text {water }}^{\text {out }}=T_{\text {water }}^{\text {sat }} \\
& x_{d, \text { water }}^{\text {out }}=\frac{m_{\text {water }}^{\text {in }} c_{p, \text { water }}\left(T_{\text {water }}^{\text {out }, \varepsilon-N T U}-T_{\text {water }}^{\text {sat }}\right)}{m_{\text {water }}^{\text {in }} \Delta h_{\text {water }, f g}}
\end{aligned}
$$

Whilst this model cannot account for cases where superheating of the exit stream occurs, it is noted that this is not likely to occur under normal power plant operating conditions.

\subsubsection{Steam Drum}

\subsubsection{Calibration Mode}

The steam drum is an inherently dynamic unit and requires a controller to set the flow rate of water circulating through the evaporator tubes in order to maintain a steady level of water in the drum. Our model assumes perfect control and that the water level in the drum remains constant under all conditions. This means that the mass flow rate of the steam leaving the drum must be the same as the flow rate of the water entering the drum:

$$
m_{\text {steam }}^{\text {out }}=m_{\text {water }}^{\text {in }}
$$

It is also assumed that the pressure inside the drum is equal to the inlet water pressure and the contents of the drum are maintained at the saturation temperature of water at the drum's operating pressure at all times - which means that the dryness fractions of the outlet water and steam streams will be 0 and 1 respectively. 
The mass flow rate of water going to the evaporator, $m_{\text {water }}^{\text {out }}$, must be sufficient to provide the energy needed to heat the steam drum's inlet water stream to its saturation temperature and then completely evaporate it, $Q_{s s}$. The mass flow rate of water to the evaporator is therefore set by the following perfect-control law:

$$
\begin{aligned}
& Q_{s s}=m_{\text {water }}^{\text {in }}\left(c_{p, \text { water }}^{\text {in }}\left(T_{\text {water }}^{\text {sat }}-T_{\text {water }}^{\text {in }}\right)+\Delta h_{\text {water }, f g}\right) \\
& Q_{s s}=m_{\text {water }}^{\text {out }} \Delta h_{\text {water }, f g}
\end{aligned}
$$

\subsubsection{Operation Mode}

In the operation mode, the perfect control law equations are modified to account for cases where the inlet water stream to the steam drum is partially evaporated. The heat transfer rate required to completely convert the inlet water to saturated steam to maintain the condition of steady-state is calculated using the following set of logical conditions which considers the cases where (1) the inlet water is sub-cooled or (2) it is partially evaporated:

$$
\begin{aligned}
& \text { If } x_{d, \text { water }}^{\text {in }}=0 \text { then } \\
& \mathrm{Q}_{s s}=m_{\text {water }}^{\text {in }}\left(c_{p, \text { water }}^{\text {in }}\left(T_{\text {water }}^{\text {sat }}-T_{\text {water }}^{\text {in }}\right)+\Delta h_{\text {water }, f g}\right) \\
& \text { ElSE } \\
& Q_{s s}=m_{\text {water }}^{\text {in }}\left(1-x_{d, \text { water }}^{\text {in }}\right) \Delta h_{\text {water }, f g}
\end{aligned}
$$

The required flow rate of water circulating through the evaporator tubes can be calculated using the obtained value of $Q_{s s}$ and the assumption that there will be perfect evaporation with no superheating of the steam in the evaporator tubes.

$$
Q_{s s}=m_{\text {water }}^{\text {out }} \Delta h_{\text {water, } f g}
$$

\subsubsection{Evaporator}

\subsubsection{Calibration Mode}

This model is used to determine the heat transfer area of every evaporator section in the HRSG. As before, perfect evaporation in every evaporator section is assumed. This in turn sets the heat transfer rate from the flue gas in the corresponding stage of the HRSG. The operational assumptions for this model are the same as those for the economiser model.

The temperature of the outlet steam stream will therefore be equal to the saturation temperature and the heat transfer duty of each evaporator section can be calculated as:

$$
Q=m_{\text {water }}^{\text {in }} \Delta h_{\text {water }, f g}
$$

The heat transfer area of each evaporator can then be calculated from equations 30-33 which were used to size the economiser sections. The value of the overall heat transfer coefficient, $U$, was taken as $0.7 \mathrm{~kW} \mathrm{~m}^{-2} \mathrm{~K}^{-1}$ (Sinnott, 2005).

\subsubsection{Operation Mode}

Once the heat transfer areas of each evaporator section have been set, the $\varepsilon$-NTU method can be used to predict the heat transfer rate and outlet temperatures of the water and flue gas streams at off-design conditions (Shah, 2003):

$$
Q=\varepsilon C_{\min }\left(T_{f g}^{i n}-T_{\text {water }}^{\text {in }}\right)
$$




$$
\begin{aligned}
& \varepsilon=1-e^{-N T U} \\
& N T U=\frac{U A}{C_{\min }}
\end{aligned}
$$

Where the heat capacity flow rate of the flue gas stream and $C_{\min }$ are given as:

$$
\begin{aligned}
& C_{f g}=n_{f g}^{i n} c_{p, f g} \\
& C_{\text {min }}=C_{f g}
\end{aligned}
$$

Equation 43, with a value of the exponential term $\alpha$ of 0.7 , will also be used to determine the value of $U$ at off-design operation of the evaporator sections.

The outlet temperature of the flue gas is given as:

$$
T_{f g}^{o u t}=T_{f g}^{i n}-\frac{Q}{C_{f g}}
$$

The temperature of the outlet steam requires consideration of the phase change boundary. If the value of $Q$ is less than the amount of heat required for perfect evaporation of the water, the water will leave as a saturated water-steam mixture and its temperature will be equal to the saturation temperature. If the value of $Q$ is greater than the amount of heat required for perfect evaporation, the water will leave as superheated steam. The temperature and vapour quality of the outlet water stream are calculated via:

$$
\begin{aligned}
& \text { If } Q \leq m_{\text {water }}^{\text {in }} \Delta h_{\text {water }, f g} \text { then } \\
& T_{\text {water }}^{\text {out }}=T_{\text {water }}^{\text {sat }} \\
& x_{d, \text { water }}^{\text {out }}=\frac{Q}{m_{\text {water }}^{\text {in }} \Delta h_{\text {water }, f g}}
\end{aligned}
$$

\section{ELSE}

$$
\begin{aligned}
& T_{\text {water }}^{\text {out }}=T_{\text {water }}^{\text {sat }}+\frac{Q-m_{\text {water }}^{\text {in }} \Delta h_{\text {water }, f g}}{m_{\text {water }}^{\text {in }} c_{p, \text { steam }}} \\
& x_{d, \text { water }}^{\text {out }}=1
\end{aligned}
$$

\subsubsection{Superheater/Reheater}

The same model is used for the superheater and reheater sections as they both describe the superheating of dry steam. The operation mode superheater/reheater model contains the same equations as the operation mode economiser model apart from equations $45-47$. Unlike the economiser and evaporator sections there are no phase change boundaries to be considered at the outlet of the superheater/reheater sections and the temperature of the outlet steam is given as:

$$
T_{\text {water }}^{\text {out }}=T_{\text {water }}^{\text {in }}+\frac{Q}{C_{\text {water }}}
$$

The value of the overall heat transfer coefficient, $U$, at full-load was taken as $0.375 \mathrm{~kW} \mathrm{~m}^{-2} \mathrm{~K}^{-1}$ (Sinnott, 2005). Equation 43, with a value of the exponential term $\alpha$ of 0.7 , will also be used to determine the value of $U$ at off-design operation of the superheaters/reheaters. 


\subsubsection{Fuel Preheater}

The natural gas feed is heated from its ambient temperature to approximately $210{ }^{\circ} \mathrm{C}$ using some of the water leaving the IP economiser in the HRSG. A calibration mode model was first implemented to size the preheater to deliver outlet fuel and water temperatures equal to the corresponding values in the full-load THERMOFLEX model. Equations 29-47 used in the calibration and operation mode economiser models are applicable here. The value of the overall heat transfer coefficient, $U$, was taken as $0.3 \mathrm{~kW} \mathrm{~m}^{-2} \mathrm{~K}^{-1}$, both at full- and part-loads, which the average value reported for organic solvents and water in shell and tube heat exchangers (Sinnott, 2005).

\subsubsection{Steam Turbine}

\subsubsection{Calibration Mode}

The steam turbine model serves the purpose of predicting the unit's output power and the temperature, pressure and vapour quality of the outlet steam. The outlet pressure of each steam turbine will be specified by the user to match the corresponding values in the full-load THERMOFLEX model. The pressure ratio across each turbine is given as:

$$
r_{t}=\frac{P_{\text {water }}^{\text {in }}}{P_{\text {water }}^{\text {out }}}
$$

There are three different scenarios that can occur during normal operation of the turbine and these are illustrated in Figure 3:

1. Dry steam (point $1^{\prime}$ ) enters the turbine and the outlet stream leaves as a partially condensed water-steam mixture under both isentropic and actual expansion (points $2 s^{\prime}$ and $2^{\prime}$ respectively)

2. Dry steam (point $1^{11}$ ) enters the turbine and the outlet stream leaves as a partially condensed water-steam mixture under isentropic expansion (point $2 s^{\prime \prime}$ ) but as superheated steam under actual expansion (point $2^{\|}$)

3. Dry steam (point $1^{\text {III }}$ ) enters the turbine and the outlet stream leaves as superheated steam under both isentropic and actual expansion (points $2 s^{\text {III }}$ and $2^{\text {III }}$ respectively)

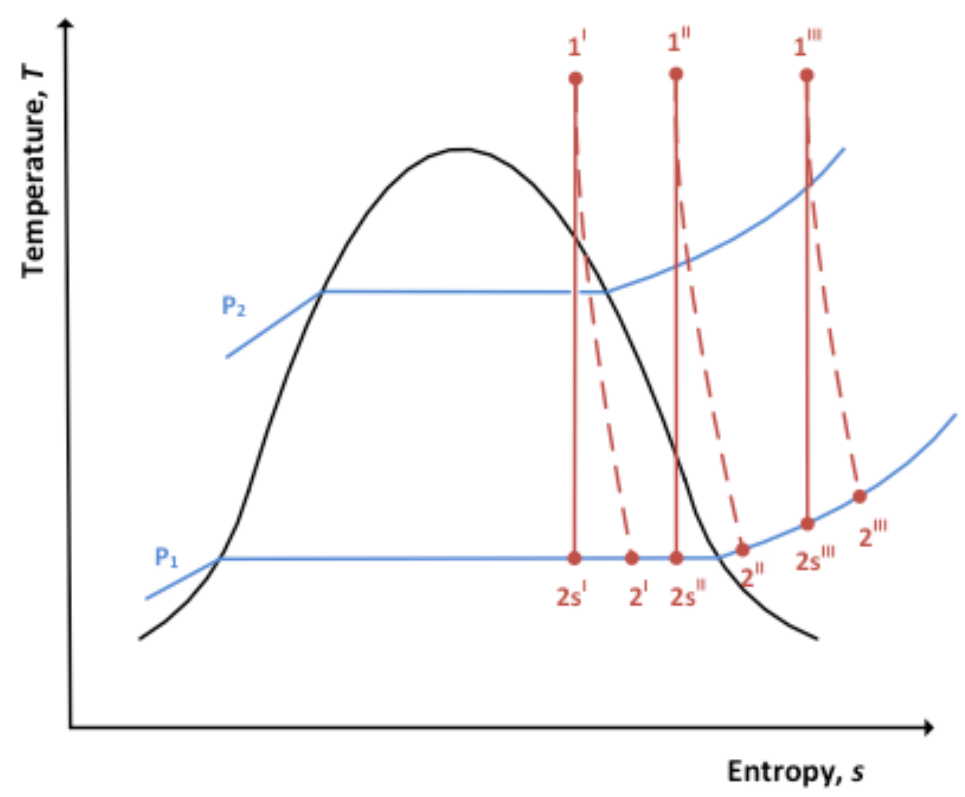

Figure 3: Steam expansion scenarios in the steam turbine

For isentropic expansion, the entropy of the stream leaving the turbine is equal to the entropy of the stream entering the turbine: 


$$
S_{\text {water }}^{\text {out ideal }}=S_{\text {water }}^{\text {in }}
$$

We know that the outlet stream will either be partially condensed or superheated and its properties must lie on the $P_{\text {water }}^{\text {out }}$ isobar. The temperature and vapour quality of the outlet stream will be calculated by first assuming that the outlet stream is partially condensed and then checking whether this assumption holds true. The dryness fraction of the outlet stream under conditions of isentropic expansion may be first estimated as $x_{d, \text { water }}^{\text {out } 1}$ :

$$
\begin{aligned}
& s_{\text {water }}^{\text {out ideal }}=s_{\text {water }, f}\left(T_{\text {water }}^{\text {sat }}, P_{\text {water }}^{\text {out }}\right) \\
& \quad+x_{d, \text { water }}^{\text {out } 1}\left[s_{\text {water }, g}\left(T_{\text {water }}^{\text {sat }}, P_{\text {water }}^{\text {out }}\right)-s_{\text {water }, f}\left(T_{\text {water }}^{\text {sat }}, P_{\text {water }}^{\text {out }}\right)\right]
\end{aligned}
$$

If $x_{d \text {,water }}^{\text {out } 1}>1$ this means that the steam is superheated. The following IF/ELSE condition can be used to determine the temperature, vapour quality and specific enthalpy of the outlet stream under conditions of isentropic expansion:

$$
\begin{aligned}
& \text { If } x_{d, \text { water }}^{\text {out } 1} \leq 1 \text { then } \\
& T_{\text {water }}^{\text {out ideal }}=T_{\text {water }}^{\text {sat }}\left(P_{\text {water }}^{\text {out }}\right) \\
& x_{d, \text { water }}^{\text {out }}=x_{d, \text { water }}^{\text {out }, 1} \\
& h_{\text {water }}^{\text {out } \text { ideal }}=h_{\text {water }, f}\left(T_{\text {water }}^{\text {out }, \text { ideal }}, P_{\text {water }}^{\text {out }}\right) \\
& +x_{d, \text { water }}^{\text {out } 1}\left[h_{\text {water }, g}\left(T_{\text {water }}^{\text {out ideal }}, P_{\text {water }}^{\text {out }}\right)-h_{\text {water }, f}\left(T_{\text {water }}^{\text {out }, \text { ideal }}, P_{\text {water }}^{\text {out }}\right)\right] \\
& \text { ELSE } \\
& S_{\text {water }}^{\text {out, ideal }}=S_{\text {water }, g}\left(T_{\text {water }}^{\text {out, ideal }}, P_{\text {water }}^{\text {out }}\right) \\
& x_{d, \text { water }}^{\text {out }}=1 \\
& h_{\text {water }}^{\text {out } \text { ideal }}=h_{\text {water }, g}\left(T_{\text {water }}^{\text {out, ideal }}, P_{\text {water }}^{\text {out }}\right)
\end{aligned}
$$

We can now use these values and the isentropic efficiency of the turbine to calculate the actual temperature, vapour quality and enthalpy of the steam leaving the turbine. The actual enthalpy of the stream leaving the turbine is calculated via:

$$
\eta_{\text {isen }}=\frac{h_{\text {water }}^{\text {in }}-h_{\text {water }}^{\text {out }}}{h_{\text {water }}^{\text {in }}-h_{\text {water }}^{\text {out } \text { ideal }}}
$$

The isentropic efficiency of each steam turbine was set to the corresponding value given in the full-load THERMOFLEX model $\left(n_{\text {isen, } H P S T}=0.86, n_{\text {isen, } I P S T}=0.90, \eta_{\text {isen, } L P S T}=0.91\right)$.

We first assume that the actual steam leaving the turbine is partially condensed and the dryness fraction of the outlet stream under conditions of actual expansion may be first estimated as, $x_{d, \text { water }}^{\text {out } 2}$ :

$$
\begin{aligned}
h_{\text {water }}^{\text {out }} & =h_{\text {water }, f}\left(T_{\text {water }}^{\text {sat }}, P_{\text {water }}^{\text {out }}\right) \\
& +x_{d, \text { water }, 2}^{\text {out }}\left[h_{\text {water }, g}\left(T_{\text {water }}^{\text {sat }}, P_{\text {water }}^{\text {out }}\right)-s_{\text {water }, f}\left(T_{\text {water }}^{\text {sat }}, P_{\text {water }}^{\text {out }}\right)\right]
\end{aligned}
$$

The actual temperature and vapour quality of the stream leaving the turbine can be calculated using the following IF/ELSE condition: 
If $x_{d, \text { water }}^{\text {out } 2} \leq 1$ then

$T_{\text {water }}^{\text {out }}=T_{\text {water }}^{\text {sat }}\left(P_{\text {water }}^{\text {out }}\right)$

$x_{d, \text { water }}^{\text {out }}=x_{d, \text { water }}^{\text {out } 2}$

ELSE

$h_{\text {water }}^{\text {out }}=h_{\text {water }, g}\left(T_{\text {water }}^{\text {out }}, P_{\text {water }}^{\text {out }}\right)$

$x_{d, \text { water }}^{\text {out }}=1$

The power output of each steam turbine is given as:

$$
W_{t}=\eta_{\text {mech }}\left(h_{\text {water }}^{\text {in }}-h_{\text {water }}^{\text {out }}\right)
$$

The mechanical efficiency of each steam turbine was set to the corresponding value given in the full-load THERMOFLEX model ( $\eta_{\text {mech }}=0.997$ for the HP, IP and LP steam turbines).

\subsubsection{Operation Mode}

The operation mode steam turbine model will contain the same equations as the calibration mode model. However, new equations are required as the outlet pressures and isentropic and mechanical efficiencies of the turbine will vary with load factor.

It was first attempted to use Stodola's law to predict the outlet pressure of each steam turbine. However, it was found that the law was very sensitive to changes in the temperature, pressure and flow rate of the inlet stream and this lead to the prediction of outlet pressures that were significantly different to the ones in the THERMOFLEX model. Thus, in the interest of computational stability, the outlet pressures of the IP and LP steam turbines were set to constant values ( $P_{\text {water }}^{\text {out } I P S T}=0.36 \mathrm{MPa}$ and $P_{\text {water }}^{\text {out } L P S T}=0.008149 \mathrm{MPa}$ ). The outlet pressure of the IP steam turbine was chosen to be sufficiently high to be suitable to provide steam to the reboiler in the capture plant. A correlation between the pressure ratio across the HP turbine and the mass flow rate of steam through this unit was created based on THERMOFLEX data:

$$
r_{t, H P S T}=0.001\left(m_{\text {water }}^{\text {in, HP ST }}\right)^{2}-0.1901 m_{\text {water }}^{\text {in, } H P S T}+12.885
$$

The values of the mechanical efficiencies of the three steam turbines and the isentropic efficiencies of the LP and IP turbines in the THERMOFLEX model did not vary by more than $0.4 \%$ and $0.92 \%$ respectively between $40-100 \%$ load. Hence these values were taken to be constant at all load factors. On the other hand, the isentropic efficiency of the HP turbine varied by $25.6 \%$ so the following correlation was derived to relate the isentropic efficiency of the HP turbine to the mass flow rate of steam flowing through it:

$$
\eta_{\text {isen, }, H P S T}=0.7388 m_{\text {water }}^{\text {in, HP ST }}+33.947
$$

\subsubsection{Water Pump}

A pump model was created to predict the power requirements of increasing the pressure of water in the LP, IP and HP circuits of the steam cycle. The same model is suitable for both the initial design and part-load operation of the plant. The power requirement of each pump is given as (Çengel, 2007):

$$
W_{\text {in }}=m_{\text {water }}^{\text {in }} \frac{1}{\eta_{\text {isen }}} \frac{1}{\eta_{\text {mech }}} V_{\text {water }}^{\text {in }}\left(P_{\text {water }}^{\text {out }}-P_{\text {water }}^{\text {in }}\right)
$$


Çengel (2007) has indicated that the temperature of the outlet water stream will be no more than $1-2 \mathrm{~K}$ greater than the temperature of the inlet stream and so the outlet is assumed to be equal to the inlet temperature.

\subsubsection{Steam Condenser}

The calibration mode condenser model is used to determine the heat transfer area and cooling water flow rate required to perfectly condense the steam leaving the LP steam turbine (with no subcooling). The same approaches used in the calibration and operation mode economiser models can be applied here. However, the cooling water outlet temperature and specified hot side temperature difference, $\Delta T_{\text {hot side, }}(\sim 10 \mathrm{~K}$ for a reasonable heat transfer area) set the minimum pressure that condensation of the LP turbine outlet steam can condense at (and hence the minimum discharge pressure from the LP turbine). The minimum condensation temperature and pressure of the outlet stream from the LP turbine are given respectively as:

$$
\begin{aligned}
& T_{\text {water }}^{\min }=T_{c w}^{\text {out }}+\Delta T_{\text {hot side }} \\
& P_{\text {water }}^{\min }=P_{\text {water }}^{\text {sat }}\left(T_{\text {water }}^{\min }\right)
\end{aligned}
$$

The value of the overall heat transfer coefficient, $U$, was taken as $1.25 \mathrm{~kW} \mathrm{~m}^{-2} \mathrm{~K}^{-1}$ which the average value reported for water-cooled condensers with aqueous condensates (Sinnott, 2005).

The model is also used to determine the electrical power required to return the hot cooling water leaving the condenser to its original inlet temperature. A simple correlation between the cooling water power requirements (in $\mathrm{MW}$ ) and the mass flow rate of cooling water was made based on data from the THERMOFLEX model:

$$
W_{i n}=\frac{(1640 / 3580) \times m_{c w}}{1000}
$$

\subsubsection{CCGT Inlet Stream Properties and Control Variables}

The CCGT model is controlled by manipulating the fuel flow rate to the combustion chamber, the total water flow rate in the steam cycle, the water flow rates going to the LP and IP sections of the steam cycle and to the fuel preheater and the outlet pressures of the LP, IP and HP water pumps. Data from the THERMOFLEX model was used to develop simple correlations between these control variables and the plant's load factor (LF):

Fuel flow rate $\left(\mathrm{kg} \mathrm{s}^{-1}\right)$ :

$$
m_{\text {fuel }}=0.1385 L F+2.3617
$$

Total water flow rate in the steam cycle $\left(\mathrm{kg} \mathrm{s}^{-1}\right)$ :

$$
m_{\text {water, total }}=0.5928 \mathrm{LF}+41.328
$$

LP splitter outlet 2 flow rate (water diverted to the LP section) $\left(\mathrm{kg} \mathrm{s}^{-1}\right)$ :

$$
m_{\text {water }, L P}=5 \times 10^{-5} L F^{3}+0.0117 L F^{2}-0.8329 L F+0.0151 e^{0.04022 L F}+26.631
$$

IP splitter outlet 2 flow rate (water diverted to the IP section of the plant) $\left(\mathrm{kg} \mathrm{s}^{-1}\right)$ :

$$
m_{\text {water }, I P}=0.0017 L F^{2}-0.1005 L F+29.445
$$

Flow rate of water diverted to the fuel preheater $\left(\mathrm{kg} \mathrm{s}^{-1}\right)$ :

$$
m_{\text {water }, F P}=-0.0008 L F^{2}+0.2274 L F+3.2886
$$


LP pump outlet pressure (MPa):

$$
P_{L P \text { pump }}^{\text {out }}=6 \times 10^{-6} L F^{2}+0.0015 L F+0.20868
$$

IP pump outlet pressure (MPa):

$$
P_{I P \text { pump }}^{\text {out }}=0.02012 L F+1.3582
$$

HP pump outlet pressure (MPa):

$$
P_{H P \text { pump }}^{\text {out }}=0.01354 L F+13.15
$$

The use of these correlations in the gPROMS model allow the user to control the plant by simply specifying the load factor and further allow an equitable comparison of both models. The air and fuel inlet streams in the gPROMS model were set to have the same compositions, temperatures and pressures as the corresponding streams in the

\begin{tabular}{|c|c|c|c|c|c|c|c|c|}
\hline & \multicolumn{6}{|c|}{ Molar Composition (\%) } & \multirow{2}{*}{$\begin{array}{c}\text { Temperature } \\
\text { (K) }\end{array}$} & \multirow{2}{*}{$\begin{array}{c}\text { Pressure } \\
\text { (MPa) }\end{array}$} \\
\hline & $\mathbf{N}_{2}$ & $\mathrm{O}_{2}$ & $\mathrm{CO}_{2}$ & $\mathrm{H}_{2} \mathrm{O}$ & $\mathrm{SO}_{2}$ & $\mathrm{Ar}$ & & \\
\hline $\begin{array}{l}\text { gPROMS and } \\
\text { THERMOFLEX } \\
\text { values }\end{array}$ & 77.292 & 20.738 & 0.030 & 1.009 & 0.000 & 0.931 & 288.2 & 0.10132 \\
\hline
\end{tabular}
THERMOFLEX model and are presented in Table 2 and Table 3 respectively.

Table 2: Air stream properties

\begin{tabular}{|c|c|c|c|c|c|c|c|}
\hline & \multicolumn{5}{|c|}{ Molar Composition (\%) } & \multirow{2}{*}{$\begin{array}{c}\text { Temperature } \\
\text { (K) }\end{array}$} & \multirow{2}{*}{$\begin{array}{c}\text { Pressure } \\
\text { (MPa) }\end{array}$} \\
\hline & $\mathrm{CH}_{4}$ & $\mathrm{C}_{2} \mathrm{H}_{6}$ & $\mathrm{C}_{2} \mathrm{H}_{6}$ & $\mathrm{CO}_{2}$ & $\mathbf{N}_{2}$ & & \\
\hline $\begin{array}{l}\text { gPROMS and } \\
\text { THERMOFLEX } \\
\text { values }\end{array}$ & 93.1 & 3.2 & 1.1 & 1.0 & 1.6 & 298.1 & 2.44 \\
\hline
\end{tabular}

Table 3: Fuel stream properties

\subsection{CCGT Modifications for PCC Integration}

The standalone CCGT plant model must be modified to include a steam extraction scheme and an exhaust gas recycling (EGR) scheme in order to be integrated with the capture plant. The process flow diagram of the modified CCGT is shown in Figure 4.

The purpose of the steam extraction scheme is to supply steam to the reboiler of the desorber in the capture plant. The steam is extracted from the LP/IP cross-over and is then sent through a desuperheater which uses the condensate leaving the reboiler to remove most of the superheat from the steam. The remaining superheat is removed using a trim cooler so that the steam entering the reboiler is always at its saturation temperature. The condensate is re-introduced into the steam cycle after the LP pump as the operating pressure in this section is always high enough to ensure that the condensate will be in its sub-cooled state. A condensate pump is needed to increase the pressure of the condensate to the outlet pressure of the LP pump.

In the EGR scheme, flue gas leaving the cold end of the HRSG is further cooled in a direct contact cooler before it is split into two streams. One stream is sent to the absorber of the capture plant and the other is mixed with the fresh air stream to the compressor in the gas turbine, after displacing an equal mass flow rate of the fresh air. 


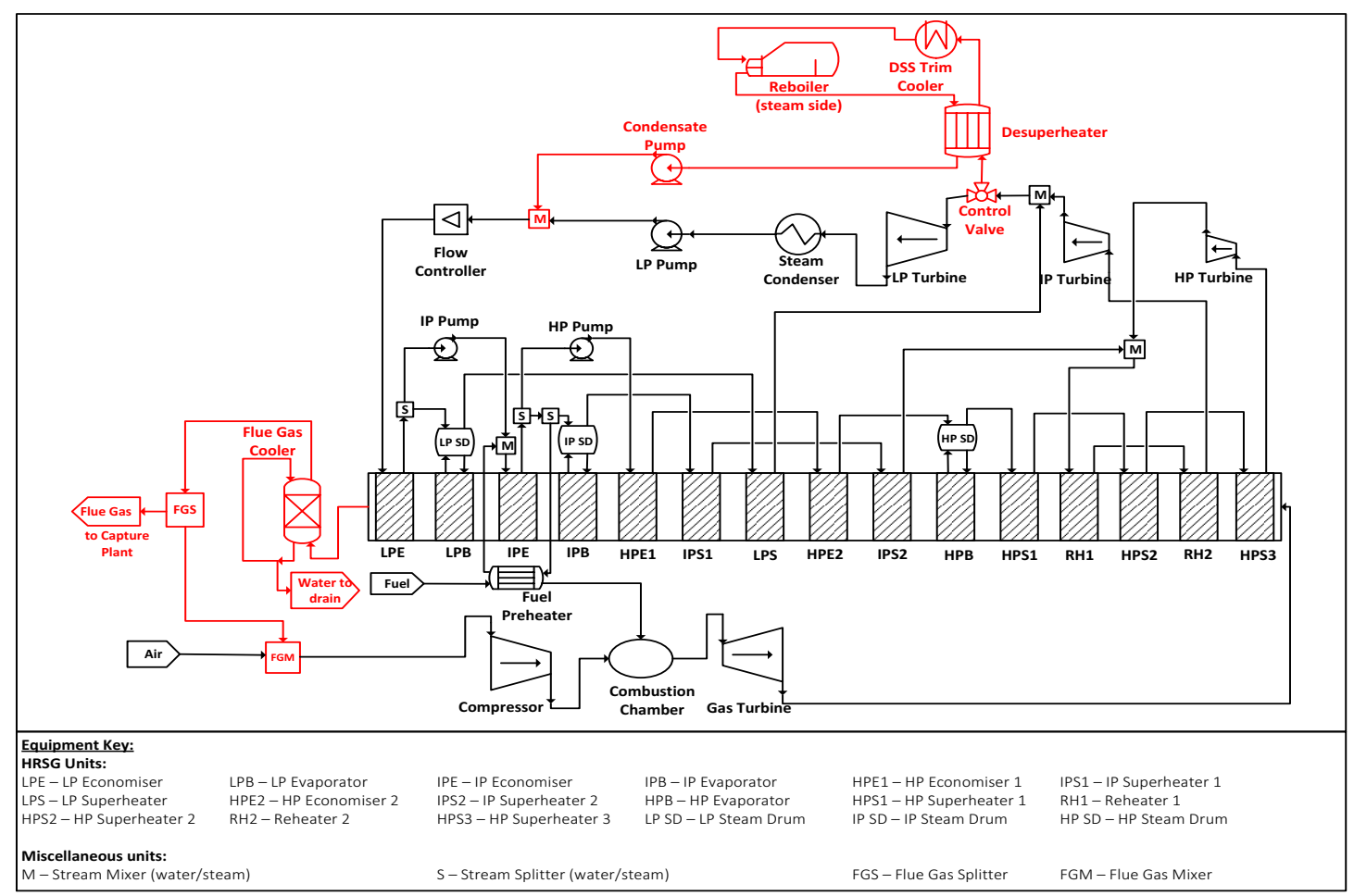

Figure 4: Process flow diagram of the modified CCGT power plant showing the steam extraction and exhaust gas recycle schemes

\subsection{Post-Combustion Capture Plant Model}

An existing dynamic model of an amine-based PCC plant (Mac Dowell, Samsatli \& Shah, 2013) was re-sized so that it was suitable for use with the CCGT plant. Figure 5 shows the configuration of the process units in the PCC plant model. The capture plant model that was implemented is limited to operating only with an inlet exhaust gas from the CCGT with a $\mathrm{CO}_{2}$ composition of $7 \mathrm{~mol} \%$. The absorption and desorption columns were sized for $70 \%$ of flooding at $100 \%$ of power plant nameplate capacity. All heat exchangers were sized for a 10K approach temperature; the reboiler was sized for a residence time of $100 \mathrm{~s}$ in the first instance and thereafter controlled to operate at a pressure of approximately $0.19 \mathrm{MPa}$ via monitoring of the solvent lean loading and manipulation of the steam supply. Finally, the overhead condenser was controlled to operate at $308 \mathrm{~K}$. The mathematical models of the units in the PCC plant are not presented in this paper but the key equipment dimensions and operating parameters are reported in the Table 4.

Table 4: Key PCC plant equipment dimensions and operating parameters

\begin{tabular}{lc}
\hline Equipment Dimension or operating parameter & Value \\
\hline Absorber packed height (m) & 40 \\
Absorber internal diameter (m) & 21 \\
Desorber packed height (m) & 25 \\
Desorber internal diameter (m) & 12 \\
Liquid-gas ratio (mol/mol) & 2.3 \\
Solvent lean-loading & 0.3 \\
$\mathrm{CO}_{2}$ capture efficiency (\%) & 90 \\
\hline
\end{tabular}

It is observed that the dimensions presented in Table 4 are in good agreement with other studies in the literature, e.g., the recent study of Rezazadeh et al. (2015). 


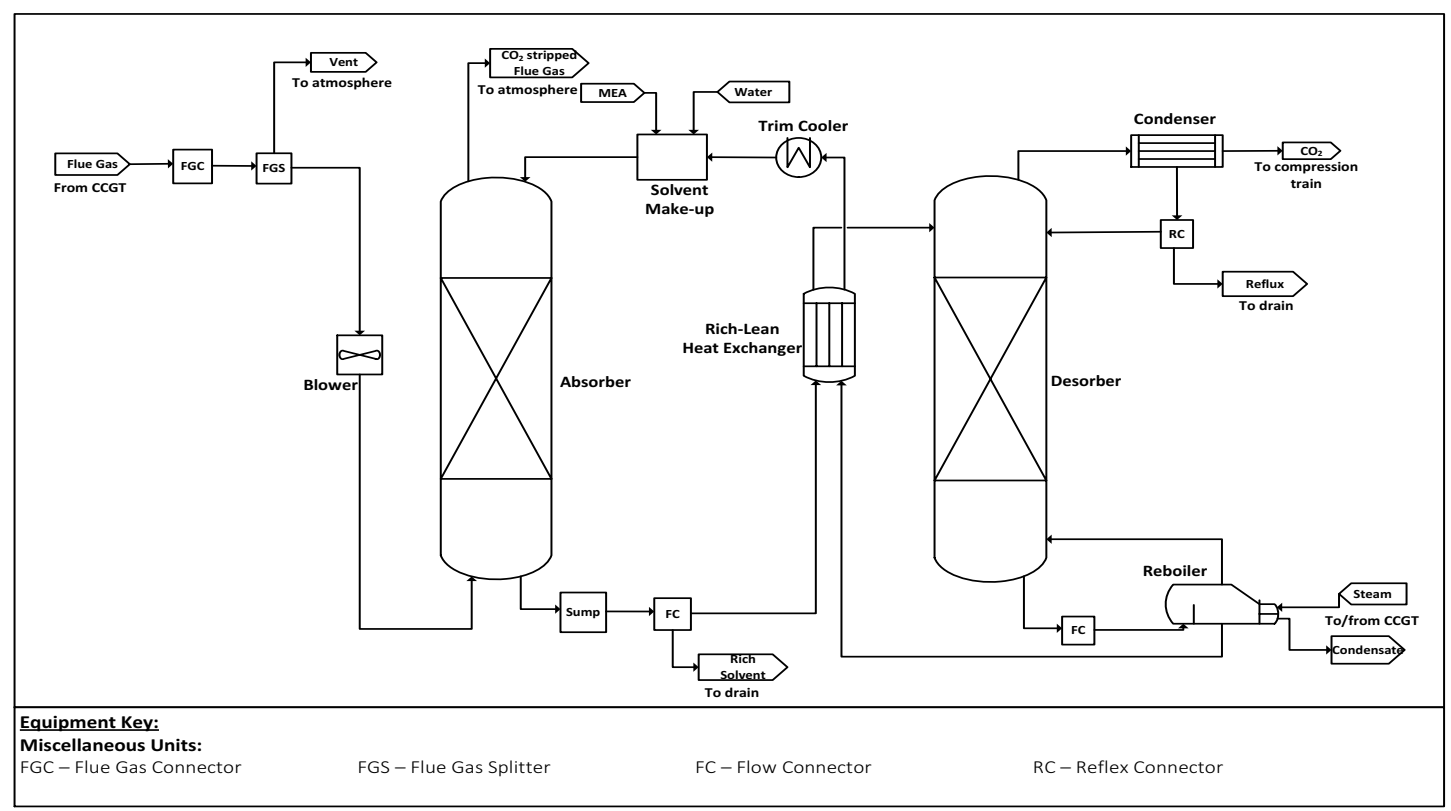

Figure 5: Process flow diagram of the post-combustion capture plant

\section{4 $\mathrm{CO}_{2}$ Compression Train}

A five-stage intercooled compression train model was created and implemented in gPROMS. The configuration follows the suggestions of Biliyok and Yeung (Biliyok \& Yeung, 2013) and Moullec and Kanniche (Moullec \& Kanniche, 2011). A process flow diagram of the compression train model is shown in Figure 6.

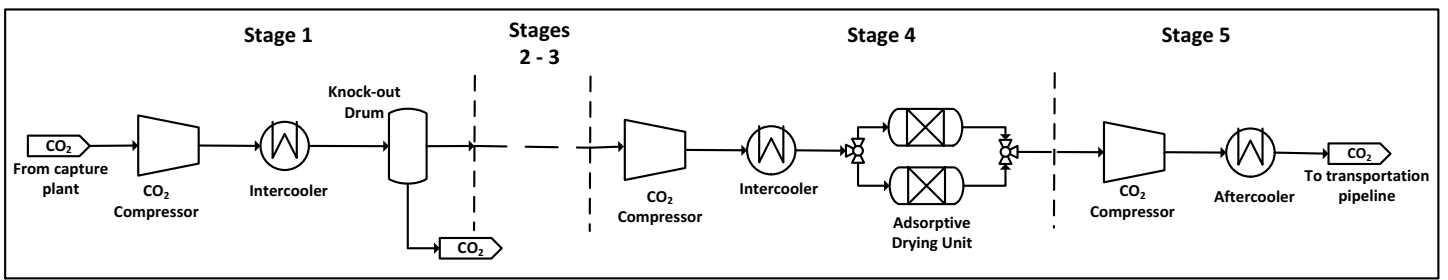

Figure 6: Process flow diagram of the $\mathrm{CO}_{2}$ compression train

The final discharge pressure will be 110 bar and the five compression stages will operate with equal pressure ratios and the compression ratio in each stage, $r_{p, \text { stage, }}$, will be (Pritchard, 2011):

$$
r_{p, \text { stage }}=\left(\frac{\text { Final pressure }(110 \mathrm{bar})}{\text { Pressure into first stage }}\right)^{1 / \text { no. of stages }}
$$

The intercoolers in every stage of the compression train will cool the gas stream down to 40 ${ }^{\circ} \mathrm{C}$ using cooling water supplied at $17{ }^{\circ} \mathrm{C}$. The first three stages contain water knock-out drums where condensed water is drawn off from the gas stream. The fourth stage contains an adsorptive drying unit which is modelled as a black-box that simply reduces the water content in the $\mathrm{CO}_{2}$ stream to its required specification of $480 \mathrm{mg} \mathrm{m}^{3}$ (Hammond, Akwe \& Williams, 2011). This model does not consider the energy requirements of regenerating the adsorption beds which would be done in practice by heating the beds with some of the hot flue gas from the CCGT. 


\subsection{Plant Cost Model}

One of the key objectives of this work is to determine the impact that applying PCC has on the levelised cost of electricity (LCOE) from the $420 \mathrm{MW}$ CCGT when considering natural gas prices predicted by DECC for the year 2030. The LCOE is calculated using the following equations (Mathieu \& Bolland, 2013). These equations are used to calculate the LCOE from the $420 \mathrm{MW}$ CCGT power plant model in the year 2030. Two cases are considered - one where the CCGT is a standalone plant and one where the CCGT is integrated with PCC. The case with PCC will consider the costs of transporting the compressed $\mathrm{CO}_{2}$ via pipeline and storing it in depleted gas fields. Cost data and the values of the other parameters that are required for use in the equations below are presented in Table 5 and Table 6.

$$
\begin{aligned}
& \operatorname{LCOE}(£ / \mathrm{MWh})=\frac{C A P \times C R F}{C F \times \text { Net power }}+(\text { \& } \& \text { costs })+C O_{2} \text { taxes paid } \\
& C R F=\frac{i(1+i)^{n}}{(1+i)^{n}-1} \\
& C A P=C A P_{C C G T}+C A P_{C C G T+P C C}
\end{aligned}
$$

$O \& M$ costs $=N G$ costs + Water costs + MEA costs $+\quad \begin{aligned} & C O_{2} \text { transportation } \\ & \text { and storage costs }\end{aligned}$

$$
\underset{(£ / \mathrm{MWh})}{N G \text { costs }}=\frac{N G \text { unit price }(£ / \mathrm{GJ}) \times \text { Net fuel input }(\text { LHV })(\mathrm{MW})}{\text { Plant net power output }(\mathrm{MW})} \times 3600 \mathrm{~s}
$$

$\underset{(£ / \mathrm{MWh})}{\text { Water costs }}=\frac{\text { Water unit price }(£ / \text { tonne }) \times \text { Make-up water rate }\left(\mathrm{kg} \mathrm{s}^{-1}\right)}{\text { Plant net power output }(\mathrm{MW})} \times 3600 \mathrm{~s}$

$\underset{(£ / M W h)}{\text { MEA costs }}=\frac{\text { MEA unit price }(£ / \text { tonne }) \times \text { Make-up MEA rate }\left(\mathrm{kg} \mathrm{s}^{-1}\right)}{\text { Plant net power output }(\mathrm{MW})} \times 3600 \mathrm{~s}$

$\begin{gathered}\mathrm{CO}_{2} \text { transportation and } \\ \text { storage costs }(£ / \mathrm{MWh})\end{gathered}=\begin{gathered}\mathrm{CO}_{2} \text { transportation and } \\ \text { storage unit cost }\left(£ / \text { tonne } \mathrm{CO}_{2}\right)\end{gathered} \times \begin{gathered}\mathrm{CO}_{2} \text { captured } \\ \left(\text { tonne } \mathrm{CO}_{2} / \mathrm{MWh}\right)\end{gathered}$

$$
\underset{(£ / \mathrm{MWh})}{\mathrm{CO}_{2} \text { taxes paid }}=\mathrm{CO}_{2} \operatorname{tax}\left(£ / \text { tonne } \mathrm{CO}_{2}\right) \times\left(\begin{array}{c}
\mathrm{CO}_{2} \text { emitted } \\
\left(\text { tonne } \mathrm{CO}_{2} / \mathrm{MWh}\right)
\end{array}\right.
$$

$\left(\begin{array}{c}\mathrm{CO}_{2} \text { emitted } \\ \left(\text { tonne } \mathrm{CO}_{2} / \mathrm{MWh}\right)\end{array}=\frac{n_{g} \times x_{\mathrm{CO}_{2}} \times\left(1-f_{\mathrm{CO}_{2}}\right)}{\text { Plant net power output }(\mathrm{MWh})} \times \frac{44 \mathrm{~kg} \mathrm{CO}_{2}}{1 \mathrm{kmol} \mathrm{CO}_{2}} \times \frac{1 \text { tonne CO}}{1000 \mathrm{~kg} \mathrm{CO}_{2}} \times 3600 \mathrm{~s}\right.$ 
$\left(\begin{array}{c}\mathrm{CO}_{2} \text { captured } \\ \left(\text { tonne } \mathrm{CO}_{2} / \mathrm{MWh}\right)\end{array}=\frac{n_{\mathrm{g}} \times x_{\mathrm{CO}_{2}} \times f_{\mathrm{CO}_{2}}}{\text { Plant net power output }(\mathrm{MWh})} \times \frac{44 \mathrm{~kg} \mathrm{CO}_{2}}{1 \mathrm{kmol} \mathrm{CO}_{2}} \times \frac{1 \text { tonne } \mathrm{CO}_{2}}{1000 \mathrm{~kg} \mathrm{CO}_{2}} \times 3600 \mathrm{~s}\right.$

Where: $C A P$ - capital cost of the project

$C A P_{C C G T}-$ capital cost of the standalone CCGT power plant

$C A P_{C C G T+P C C}$ - capital cost of the CCGT with integrated PCC

$C R F$ - capital recovery factor

$C F$ - capacity factor (average plant load)

O\&M costs - operation and maintenance costs

$i$ - interest rate

$n$ - plant lifetime

$n_{f g}$ - molar flow rate of flue gas going to the PCC plant

$x_{\mathrm{CO} 2}-$ mole fraction of $\mathrm{CO}_{2}$ in the flue gas going to the PCC plant

$f_{\mathrm{CO} 2}-$ fraction of the $\mathrm{CO}_{2}$ in the flue gas that is captured

Table 5: Parameter values required to calculate the levelised cost of electricity

\begin{tabular}{|c|c|c|}
\hline Cost or Parameter & Value & Source \\
\hline $\mathrm{CAP}_{\text {CCGT }}$ & $£ 229.5$ million & IECM software version 8.0 .2 \\
\hline $\mathrm{CAP}_{\mathrm{CCGT}+\mathrm{PCC}}$ & $£ 352.6$ million & IECM software version 8.0.2 \\
\hline MEA unit price & $£ 1,601 /$ tonne MEA & Biliyok \& Yeung (2013) \\
\hline Water unit price & $£ 0.181 /$ tonne water & Sinnott (2005) \\
\hline $\begin{array}{l}\mathrm{CO}_{2} \text { transportation and } \\
\text { storage cost per unit }\end{array}$ & $£ 4 /$ tonne $\mathrm{CO}_{2}$ & $\begin{array}{l}\text { For transportation via pipeline and } \\
\text { storage in depleted gas fields } \\
\text { (Hammond, Akwe \& Williams, 2011) }\end{array}$ \\
\hline Plant life, $n$ & 25 years & (Mathieu \& Bolland, 2013) \\
\hline $\begin{array}{l}\text { Average capacity factor } \\
\text { over the plant's life, } C G\end{array}$ & $70 \%$ & Assumed \\
\hline Interest rate, $i$ & $10 \%$ & Assumed \\
\hline $\mathrm{CO}_{2}$ tax & $£ 0 /$ tonne CO2 & Assumed \\
\hline $\begin{array}{l}\text { Fraction of } \mathrm{CO}_{2} \text { captured, } \\
f_{\mathrm{CO} 2}\end{array}$ & 0.9 & Assumed \\
\hline
\end{tabular}

Table 6: Natural gas price predictions for the UK in 2030 (DECC, 2012)

\begin{tabular}{ccc}
\hline Low (£/GJ (LHV)) & Central (£/GJ (LHV)) & High (£/GJ (LHV)) \\
\hline 3.90 & 6.82 & 9.74
\end{tabular}

It should be noted that only the natural gas prices used in this work are specific to the year 2030. All of the other prices quoted are current and therefore may not reflect the prices in the year 2030. It has also been assumed that there are no $\mathrm{CO}_{2}$ emissions taxes in effect. Although this will not be the case in 2030 , this was purposely done in order to calculate the tax rate that will be needed to make the LCOE of the plant without PCC equal to that of the plant with PCC. In addition, for the purposes of simplicity, the calculations do not include site operating taxes, maintenance costs and labour costs.

Power producers will only have an incentive to apply carbon capture if $\mathrm{CO}_{2}$ taxes are put into legislation that will make the LCOE for a CCGT without CCS higher than that for a plant with PCC. The $\mathrm{CO}_{2}$ tax rate that will make the LCOE of the two cases equal can be calculated as the cost of $\mathrm{CO}_{2}$ avoided (Wilcox, 2012): 
Cost of $\mathrm{CO}_{2}$ Avoided $=\frac{[\mathrm{LCOE}]_{\text {with } \mathrm{CCS}}-[\mathrm{LCOE}]_{\text {without CCS }}}{\left[\text { tonne } \mathrm{CO}_{2} \text { Emitted } / \mathrm{MW}\right]_{\text {without } \mathrm{CCS}}-\left[\text { tonne } \mathrm{CO}_{2} \text { Emitted } / \mathrm{MW}\right]_{\text {with } \mathrm{CCS}}}$

\section{Model Validation}

The standalone $420 \mathrm{MW}$ CCGT power plant model developed in this work was validated using the Thermoflow THERMOFLEX model of a triple-pressure reheat CCGT with a Siemens SGT5-4000F gas turbine. We have selected power plant efficiency, net power output and the HRSG temperature profile at full and part load as key variables against which to validate the performance of our model.

Plant efficiency (LHV) is defined as follows:

$$
n_{\text {plant }}=\frac{W_{\text {plant }}}{m_{\text {fuel }} \times L H V_{\text {fuel }}} \times 100
$$

Where the net power output of the plant $\left(W_{\text {plant }}\right)$ is given as the sum of the power produced by the gas turbine, LP, IP and HP steam turbines minus the power consumed by the compressor in the gas turbine, the LP, IP and HP pumps and the power needed to cool the water used in the steam condenser.

The differences are expressed in terms of the percentage absolute deviations (\%AD) of the values predicted by the gPROMS model compared to the corresponding values in the THERMOFLEX model. The \%AD of variable $i$ at load $j$ calculated as:

$$
\% A D_{i, j}=\frac{g_{i, j, c a l c}-g_{i, j, T F}}{g_{i, j, T F}} \times 100
$$

Where: $g_{i, j, c a l c}$ - calculated value of variable $i$ at load $j$

$g_{i, j, T F}-$ THERMOFLEX value of variable $i$ at load $j$

The overall deviation of the gPROMS CCGT from the THERMOFLEX equivalent was measured by comparing the deviations of the temperatures, pressures and vapour qualities or compositions (where applicable) of every stream in the two models over all load factors. The following equation was used to calculate the percentage average absolute deviation (\%AAD) of the CCGT model as a whole:

$$
\% A A D=\frac{1}{n_{\text {var }}} \sum_{i=1}^{n_{\mathrm{var}}}\left(\frac{1}{n_{L F}} \sum_{j=40 \%}^{100 \% \text { load }} \frac{g_{i, j, \text { calc }}-g_{i, j, T F}}{g_{i, j, T F}}\right) \times 100
$$

Where: $n_{\text {var }}-$ number of variables

$n_{L F}-$ number of load factor operating points

$g_{i, j, c a l c}$ - calculated value of variable $i$ at load $j$

$g_{i, j, T F}-$ THERMOFLEX value of variable $i$ at load $j$

Comparisons between the net power outputs and plant efficiencies (LHV) ( $\left.\eta_{\text {plant }}\right)$ of the gPROMS and THERMOFLEX models are given in Table 7.

The percentage absolute deviations of the plant power output and plant efficiency values increase as the load factor is decreased. The results obtained below load factors of $50 \%$ are considered unreliable as indicated by the \%ADs of these parameters exceeding $5 \%$. This trend is primarily influenced by the growing deviation in the net power output predicted by the 
gas turbine model with decreasing load and to a lesser extent by the deviations in the power outputs predicted by the HP, IP and LP steam turbine models. We note that the model calibration was performed at $100 \%$ power plant load. Thus all calculations performed at offdesign conditions can be regarded as predictions, with total model accuracy within $4.1 \%$, noting that the performance of our model reduces at load factors below $50 \%$. However, based on some of our recent work (Mac Dowell \& Staffell, 2016), we have found that thermal power plants will likely operate at greater than $50 \%$ load whilst contributing to the electricity system. Once the demand requires the power plant to contribute less than $50 \%$ of its nameplate capacity, it will likely be outcompeted by a more efficient generator operating at full load and will therefore be displaced from the market. For this reason, we propose that our current model is sufficient for the task of describing the part-load behaviour of decarbonised CCGT power plants. Finally, the gPROMS model describing the thermal behaviour in the HRSG at design point was observed to reproduce that of the THERMOFLEX model $2.860 \%$.

Table 7: Comparison of the net plant power output (MW) and plant efficiency (LHV) predicted by the gPROMS and THERMOFLEX models. The Absolute-relative Deviation (\%AD) between the gPROMS model and the THERMOFLEX model are presented in the columns and the Average Absolute-relative Deviation (\%AAD) is presented in the final column for each performance indicator.

\begin{tabular}{ccccccc}
\hline \multirow{2}{*}{ Load } & \multicolumn{3}{c}{ Plant power output (MW) } & \multicolumn{3}{c}{ Plant efficiency (LHV) (\%) } \\
\cline { 2 - 7 } & TF & gPROMS & \%AD & TF & gPROMS & \%AD \\
\hline 100 & 415.5 & 420.8 & 1.275 & 51.47 & 51.84 & 0.724 \\
90 & 383.2 & 383.4 & 0.047 & 51.06 & 51.65 & 1.152 \\
80 & 340.9 & 345.6 & 1.355 & 50.46 & 51.35 & 1.763 \\
70 & 298.7 & 307.1 & 2.819 & 49.67 & 50.88 & 2.431 \\
60 & 256.4 & 268.3 & 4.652 & 48.58 & 50.23 & 3.391 \\
50 & 214.1 & 229.5 & 7.213 & 46.48 & 49.36 & 6.211 \\
40 & 171.6 & 190.4 & 10.959 & 42.63 & 48.13 & 12.902 \\
\hline \%AD & \multicolumn{7}{c}{$\mathbf{4 . 0 4 6}$} \\
\hline
\end{tabular}

The net power output predicted by the gPROMS gas turbine model (i.e. the power output of the turbine minus the power consumption of the compressor) decreased significantly less with decreasing load factor compared to the corresponding THERMOFLEX value. It was not possible to compare the power consumption of the gPROMS compressor model and the power output of the gPROMS turbine model to their corresponding THERMOFLEX values as these values were not reported individually in the THERMOFLEX model. It is suggested that the theoretical design equations that were used to calculate the power input required by the compressor at part-load (equations 1-3) are less accurate in this application as they do not consider the mechanical aspects of the compressor and hence underestimate the power input required during part-load operation. Similarly, equations 21-23 that were used to calculate the power output of the turbine are believed to be inaccurate for the same reason.

The power outputs predicted by the gPROMS LP, IP and HP steam turbines decreased more with decreasing load factor compared to the corresponding THERMOFLEX values. These deviations were exacerbated by two assumptions that were made in the gPROMS model: (1) there were no pressure drops in the water/steam side of the HRSG thus affecting the inlet pressures to the HP and IP turbines and (2) the outlet pressures of the IP and LP turbines were assumed to be constant.

A comparison of the HRSG temperature profiles in the gPROMS and THERMOFLEX models running at full load is shown in Figure 7 . Whilst excellent agreement with the Thermoflow models is observed, those dissimilarities that are observed are attributed to the differences in the heat capacities of the water and steam predicted by the gPROMS and THERMOFLEX models and the fact that the flue gas enters the HRSG in the gPROMS model at a slightly higher temperature than in the THERMOFLEX model. 


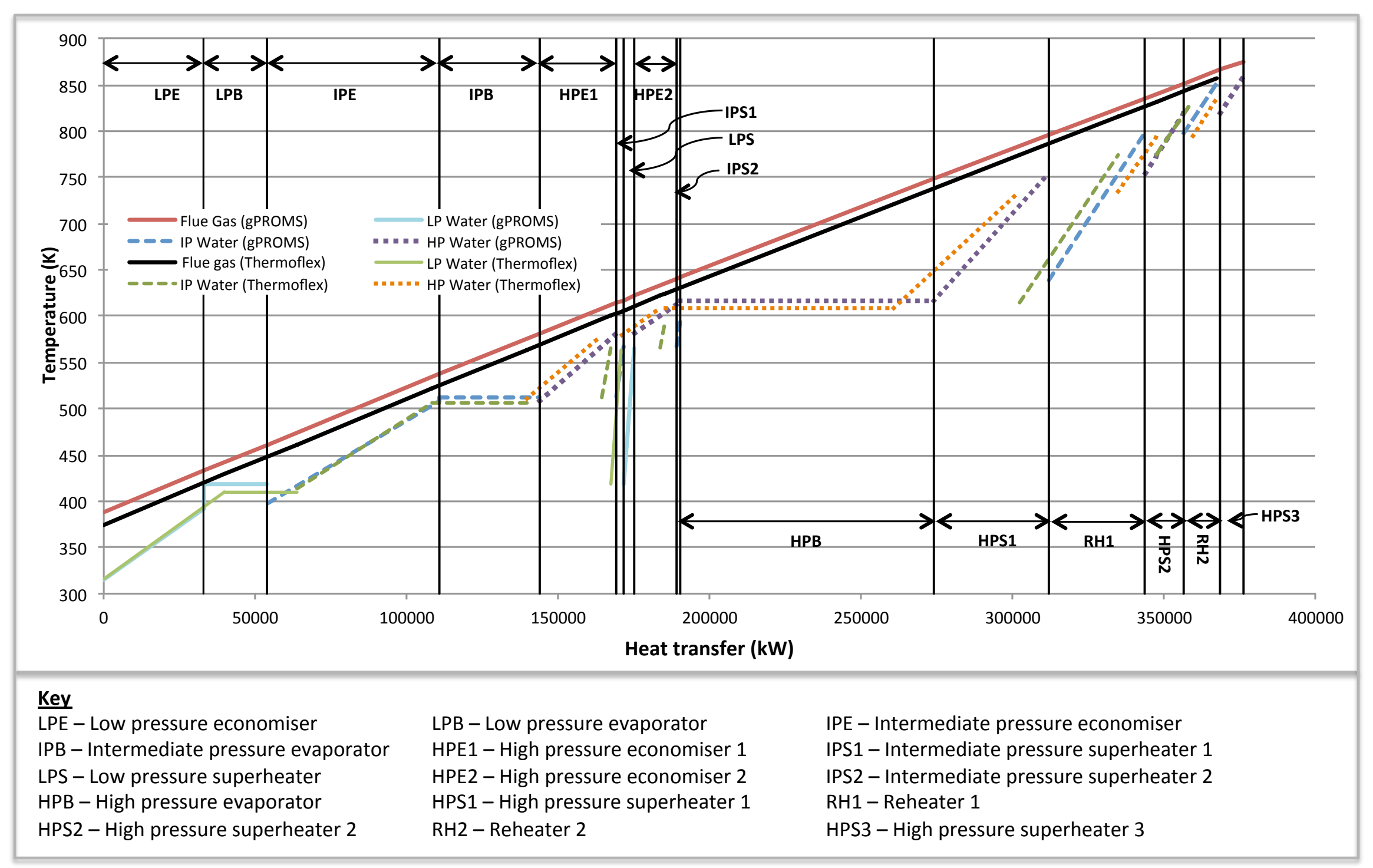

Figure 7: Comparison of the full-load HRSG profiles in the gPROMS and THERMOFLEX models 


\section{Results and Discussion}

This section focuses on the impact that the application of post combustion carbon capture plant with $\mathrm{CO}_{2}$ compression to 110 bar has on the performance of the $420 \mathrm{MW}$ natural gasfired CCGT power plant in terms of its power output and levelised cost of electricity (LCOE). This work will also examine the effects that exhaust gas recycle (EGR) has on the performance of the plant in terms of power output and exhaust gas composition. In the case with PCC, the CCGT plant will be set to deliver an exhaust gas with a $\mathrm{CO}_{2}$ concentration of $7 \%$ (made possible by the use of EGR) to the PCC plant at all load factors. The PCC model was specified so as to operate with a constant $\mathrm{CO}_{2}$ capture efficiency of $90 \%$, i.e., $90 \%$ of the $\mathrm{CO}_{2}$ in the flue gas stream is captured.

\subsection{Impact of EGR on the Performance of the CCGT}

This section will evaluate how varying the level of exhaust gas recycle (EGR) between 0 and $45 \%$ affects the composition of the flue gas going to the capture plant, the composition of the air being fed to the combustion chamber and its effect on plant power output. The maximum EGR ratio possible at each load factor will also be examined.

\subsubsection{Effect of EGR Ratio on the Compositions of the Flue Gas and Air to the Combustion Chamber}

Figure 8 illustrates how the compositions of the flue gas leaving the CCGT and the air to the combustion chamber change respectively as the EGR ratio is varied between $0-45 \%$ while the CCGT is operated at full load.

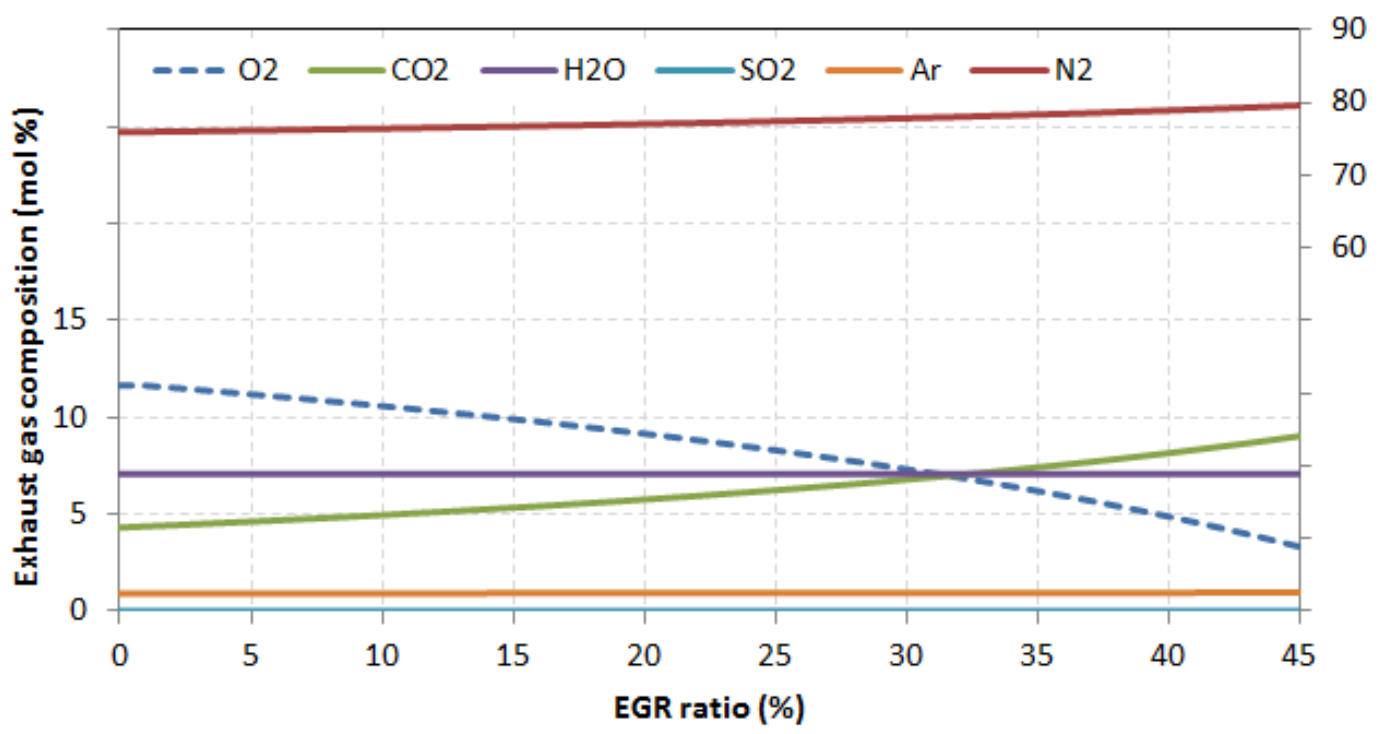

Figure 8: Effect of EGR ratio on the composition of the exhaust gas leaving the CCGT at full-load

It can be seen from Figure 9 that increasing the level of EGR from $0-45 \%$ when the CCGT is operating at full-load increases the molar concentration of $\mathrm{CO}_{2}$ in the exhaust gas from $4.32 \%$ to $9.04 \%$ whilst decreasing the molar concentration of $\mathrm{O}_{2}$ in the air to the combustion chamber from $20.74 \%$ to $13.03 \%$. It is gratifying to note that the results presented in Figure 8 are consistent with those presented by Canepa et al. (2013). 


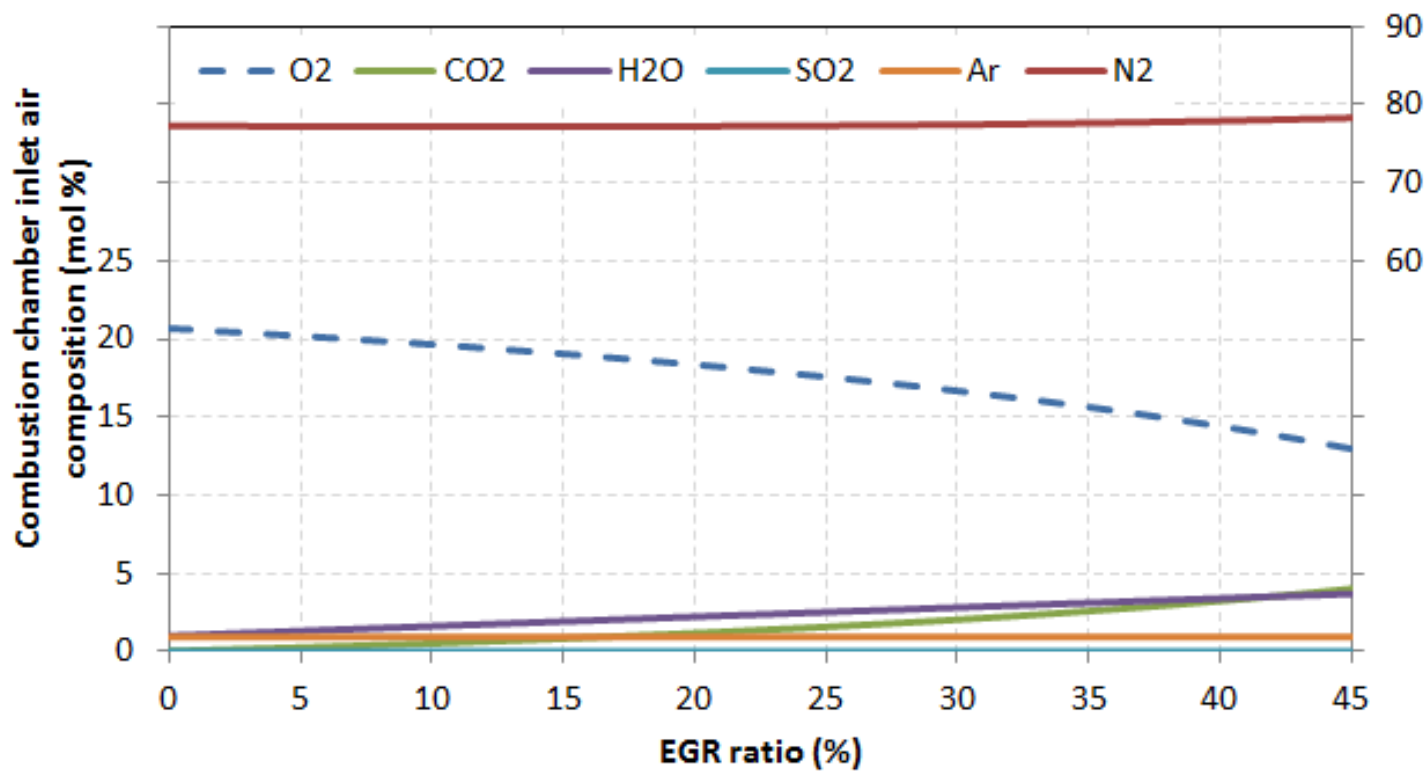

Figure 9: Effect of EGR ratio on the composition of the inlet air to the combustion chamber at full-load

The effects of varying the EGR ratio between $0-45 \%$ on the $\mathrm{CO}_{2}$ and $\mathrm{O}_{2}$ concentrations in the flue gas and in the air to the combustion chamber respectively at plant load factors between $40-100 \%$ are shown in Figure 10 and Figure 11.

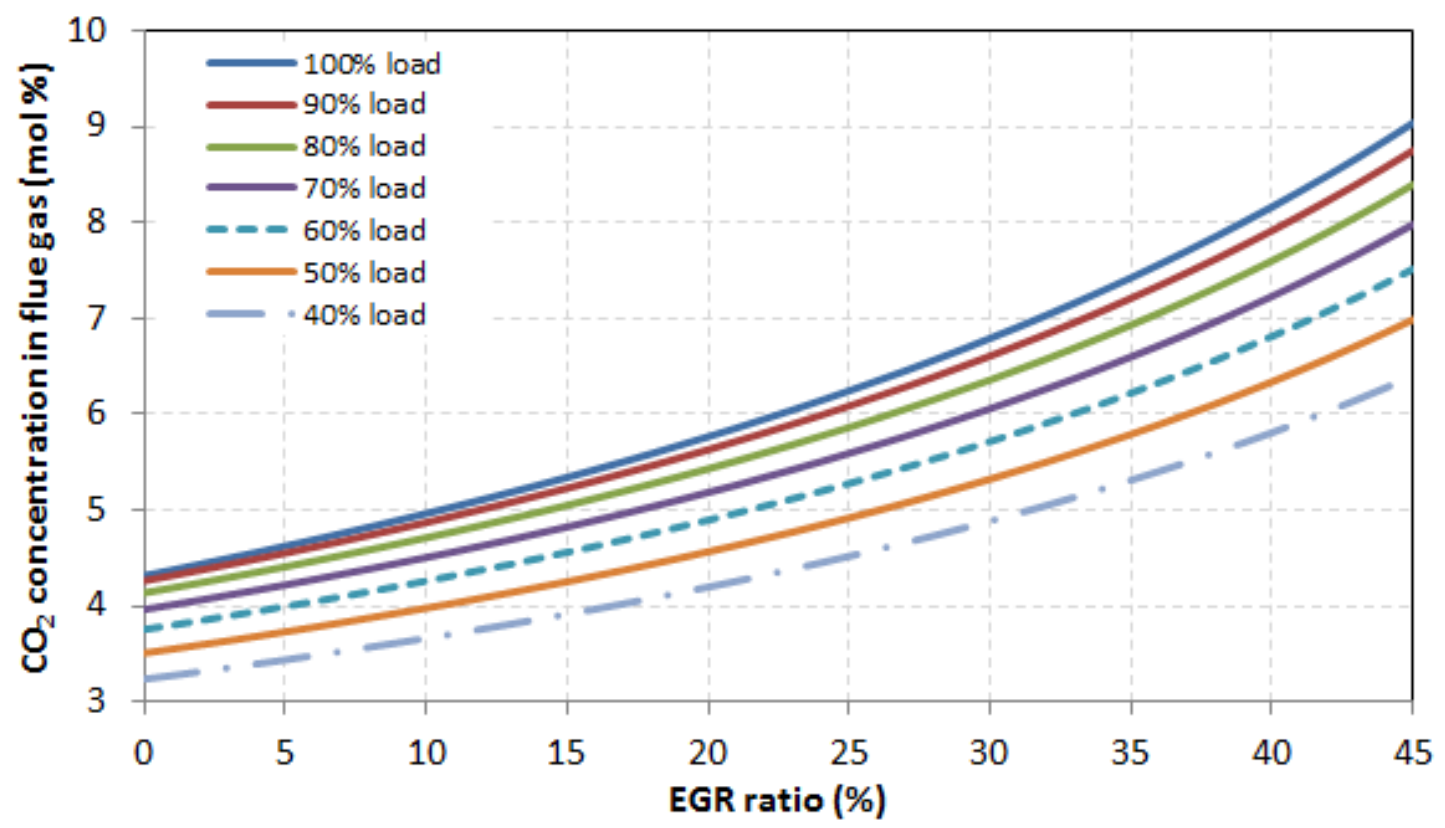

Figure 10: Effect of EGR ratio on the $\mathrm{CO}_{2}$ concentration in the exhaust gas leaving the CCGT whilst operating at load factors between $40-100 \%$

As plant load drops, increased EGR has a reduced influence on the $\mathrm{CO}_{2}$ concentration in the flue gas and on the $\mathrm{O}_{2}$ concentration in the combustion chamber's inlet air. The reason for this is that the CCGT's controls increase the excess air ratio to the combustion chamber to reduce the plant's output power. This leads to the production of flue gas that is more dilute in $\mathrm{CO}_{2}$ at lower loads. 


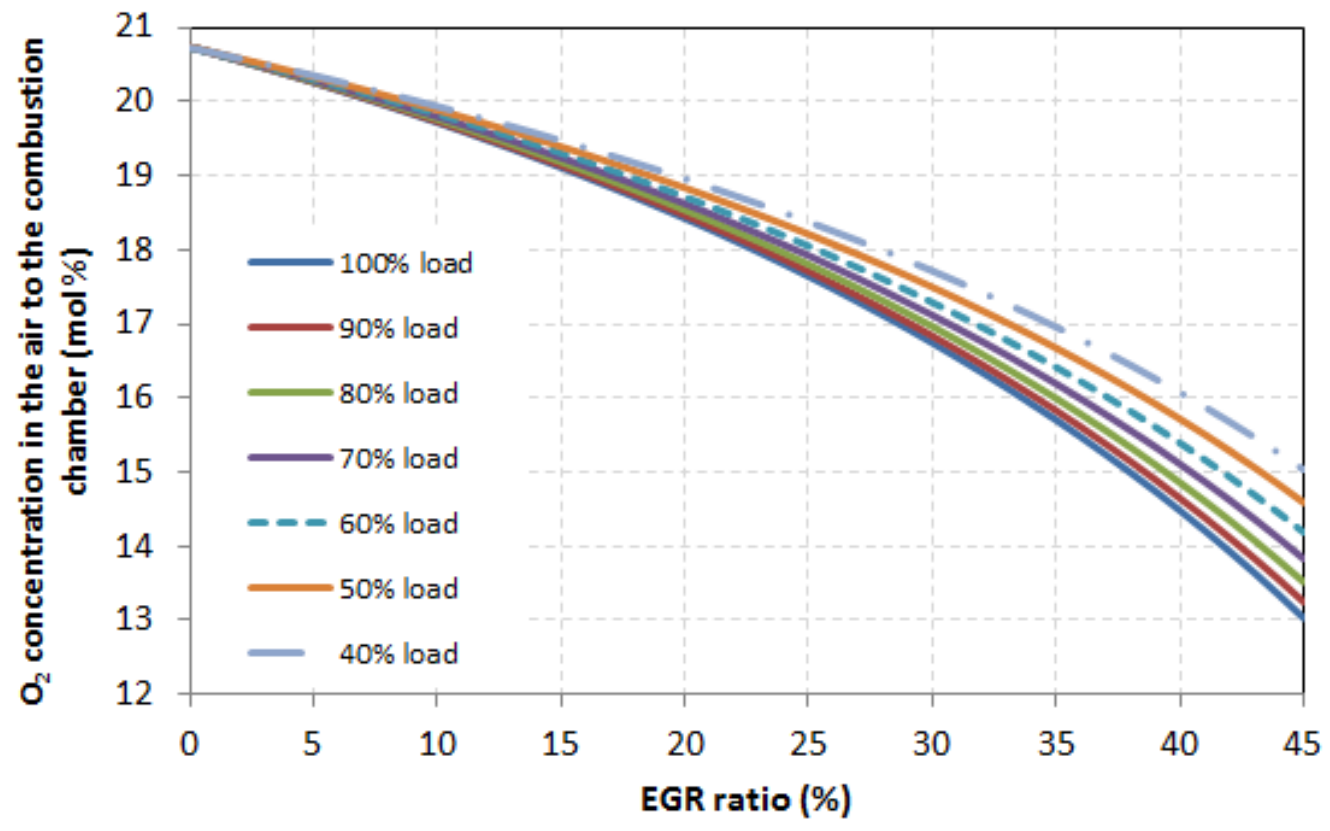

Figure 11: Effect of EGR ratio on the $\mathrm{O}_{2}$ concentration in the inlet air to the combustion chamber when the CCGT is operating at load factors between $40-100 \%$

\subsection{Effect of EGR ratio on power plant output}

It was found that increasing the EGR ratio from $0-45 \%$ causes a small decrease in the plant's net power output by approximately $1 \mathrm{MW}$ whilst the plant is operated at any load factor between $40-100 \%$ as shown in Figure 12.

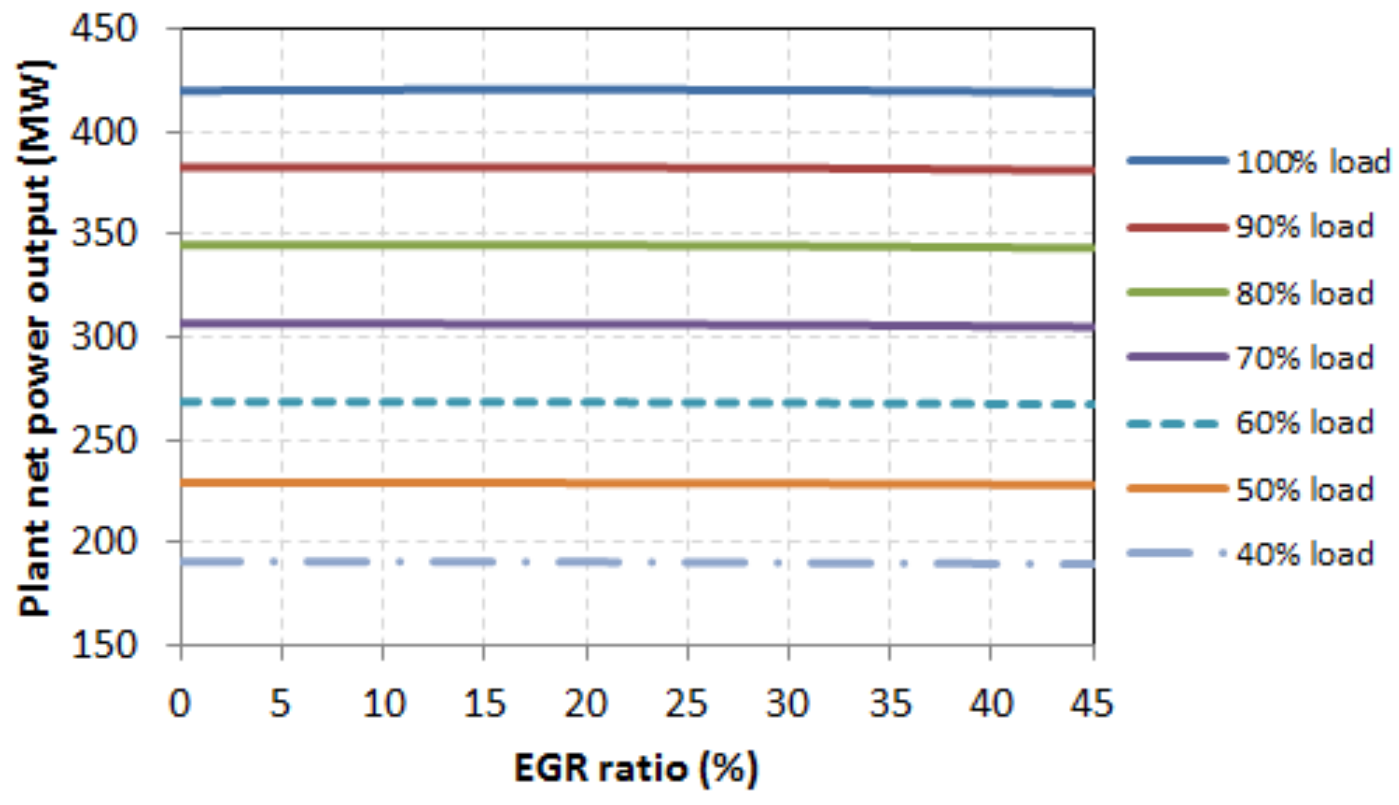

Figure 12: Effect of EGR ratio on net power output of the CCGT

As the EGR ratio increases, the temperature of the inlet air to the compressor will increase as a greater proportion of warm flue gas at $40^{\circ} \mathrm{C}$ is mixed with fresh air air which is at $15^{\circ} \mathrm{C}$. An increase in the inlet temperature to the compressor, with molar flow rate held constant, might be expected increase the work requirement of the compressor (see equations 1-7). However, the exhaust gas entering the gas turbine will be at a slightly higher temperature and pressure 
and this will in turn increase the power output of the turbine (see equations 21-26) thus counteracting the increased power requirement of the compressor. However, the outlet pressure of the gas turbine in the model implemented in this work was set to a constant value of $0.1035 \mathrm{MPa}$ due to the highly sensitive nature of Stodola's law, which was used to predict the part-load behaviour of the turbine. This means that the gas turbine equations set the flow rate of air that must enter the compressor at each load factor so that the exhaust gas leaves the turbine at $0.1035 \mathrm{MPa}$. An increase in the temperature of the inlet stream to the compressor causes the system to reduce the molar flowrate of the inlet stream. This in turn reduces the power requirement of the compressor and the power output of the gas turbine is also reduced but by a slightly greater magnitude which results in the very slight decrease in the plant's net power output that was observed when the EGR ratio was increased from 0$45 \%$.

\subsection{Maximum EGR Ratios}

Operating the CCGT with the highest possible EGR ratio is desirable because it increases the concentration of $\mathrm{CO}_{2}$ in the flue gas to the capture plant which makes the capture process less energy intensive. However, the EGR ratio is limited to $35-40 \%$ in practice (Li et al., 2011 and Merkel et al., 2013) as increased an increasing EGR ratio reduces the level of oxygen that is available in the air to the combustion chamber. The $\mathrm{O}_{2}$ concentration in the inlet air to the combustion chamber should be greater than $16 \%$ to prevent the production of significant quantities of unburned hydrocarbons and carbon monoxide ( $\mathrm{Li}$ et al., 2011). The maximum EGR ratio is therefore the value that leads to an $\mathrm{O}_{2}$ concentration of $16 \%$ in the inlet air to the combustion chamber. The maximum EGR ratio increases as the plant's load factor decreases as can be seen in Figure 13. This effect results from the increase in the air-fuel ratio in the combustion chamber as load factor decreases.

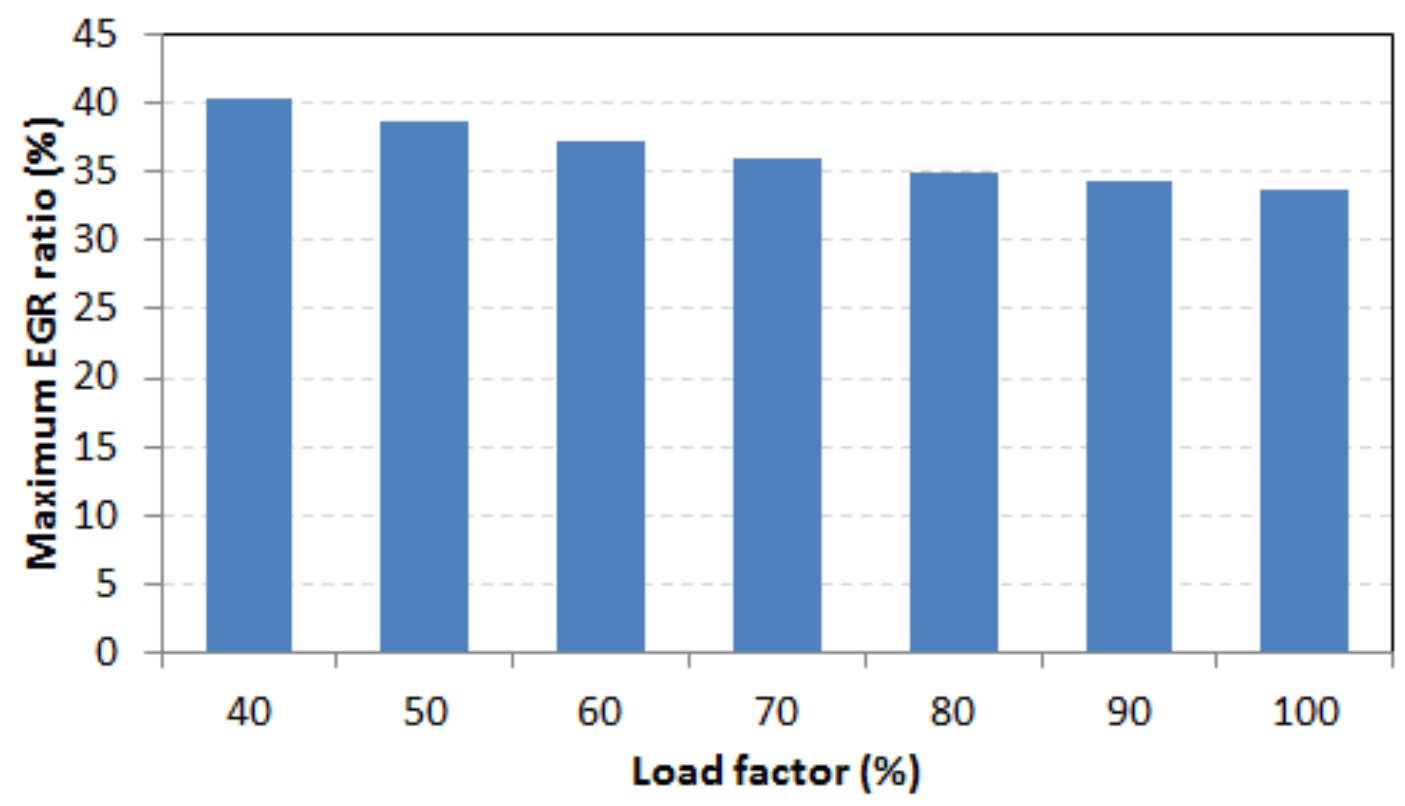

Figure 13: Maximum EGR ratios at plant load factors between $40-100 \%$

In the remainder of this paper, we continue with an EGR of approximately $35 \%$ - consistent with the maximum EGR possible for practical applications, as illustrated in Figure 13. This gives us a $\mathrm{CO}_{2}$ concentration of approximately $7 \mathrm{~mol} \%$ at the inlet to the $\mathrm{CO}_{2}$ capture process, and is consistent with the conclusions of Pan et al. (Pan et al., 2016).

\subsection{Plant Power Output with and without PCC}

This section presents an evaluation of the impacts that applying PCC has on the gross and net power outputs and efficiency of the 420 MW CCGT model. The analysis examines how 
the contributions of the gas and steam turbines to the gross power output of the plant change when PCC is applied. The relative contributions of the various components of the PCC plant to the associated energy penalty will also be examined as well as the changes in reboiler duty and the steam extraction rate over part-load.

\subsubsection{Gross and Net Power Outputs with and without PCC}

As might be expected, the gross and net power outputs of the CCGT power plant were reduced when PCC was applied as shown in Figure 14 and Table 8.

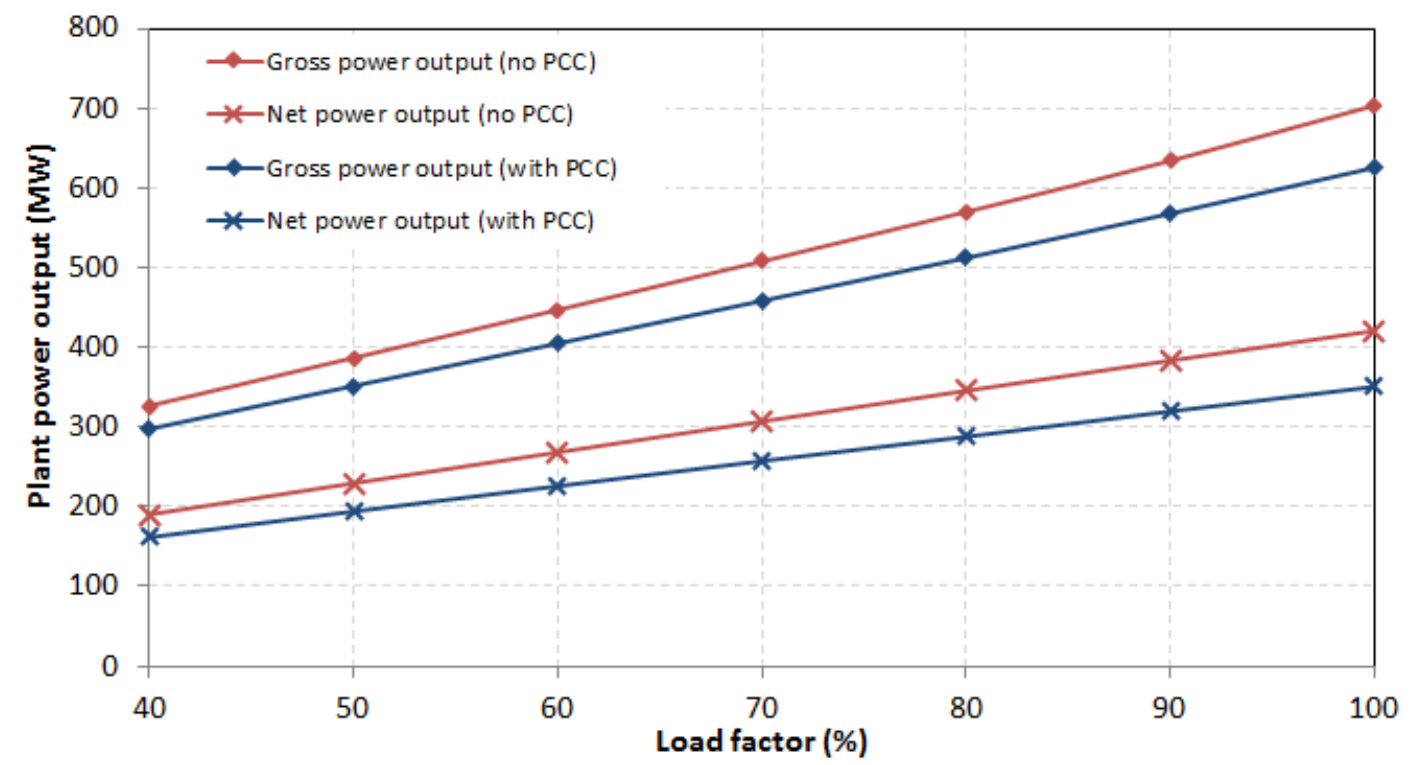

Figure 14: Gross and net power outputs from the CCGT with and without PCC

The application of PCC led to a $16.7 \%$ drop in the net power output of the plant at full-load. This is in good agreement with similar studies in the literature (Amrollahi, Ertesvag \& Bolland, 2011, Jordal et al., 2012 and Dillon et al., 2013 and Kuramochi et al., 2009).

Table 8: Gross and net power outputs from the CCGT with and without PCC

\begin{tabular}{ccccc}
\hline \multirow{2}{*}{ Load factor (\%) } & \multicolumn{2}{c}{ Plant without CCS } & \multicolumn{2}{c}{ Plant with CCS } \\
\cline { 2 - 5 } & $\begin{array}{c}\text { Gross power output } \\
\text { (MW) }\end{array}$ & $\begin{array}{c}\text { Net power } \\
\text { output (MW) }\end{array}$ & $\begin{array}{c}\text { Gross power output } \\
\text { (MW) }\end{array}$ & $\begin{array}{c}\text { Net power } \\
\text { output (MW) }\end{array}$ \\
\hline 100 & 703.4 & 420.8 & 625.5 & 350.6 \\
90 & 634.0 & 383.4 & 567.8 & 319.7 \\
80 & 569.9 & 345.6 & 512.1 & 287.9 \\
70 & 507.8 & 307.1 & 458.3 & 257.4 \\
60 & 446.9 & 268.3 & 404.9 & 226.0 \\
50 & 386.8 & 229.5 & 351.6 & 194.1 \\
40 & 326.7 & 190.4 & 297.7 & 161.6 \\
\hline
\end{tabular}

It was further observed that the percentage drop in net plant power output decreased slightly with decreasing load factor to $15.8 \%$ at $60 \%$ load, except for an increase at $80 \%$ load. 


\subsubsection{Net Plant Efficiency}

The standalone CCGT was found to have a net plant efficiency of $51.84 \%$ at full-load, dropping to an efficiency of $50.23 \%$ at $60 \%$ load as shown in Figure 15 . This is a satisfactory result as it is representative of the state-of-the-art CCGT power plants that are currently deployed (Turconi et al., 2014) although it is also noted that is possible for CCGT power plants to approach a net efficiency of $60 \%$.

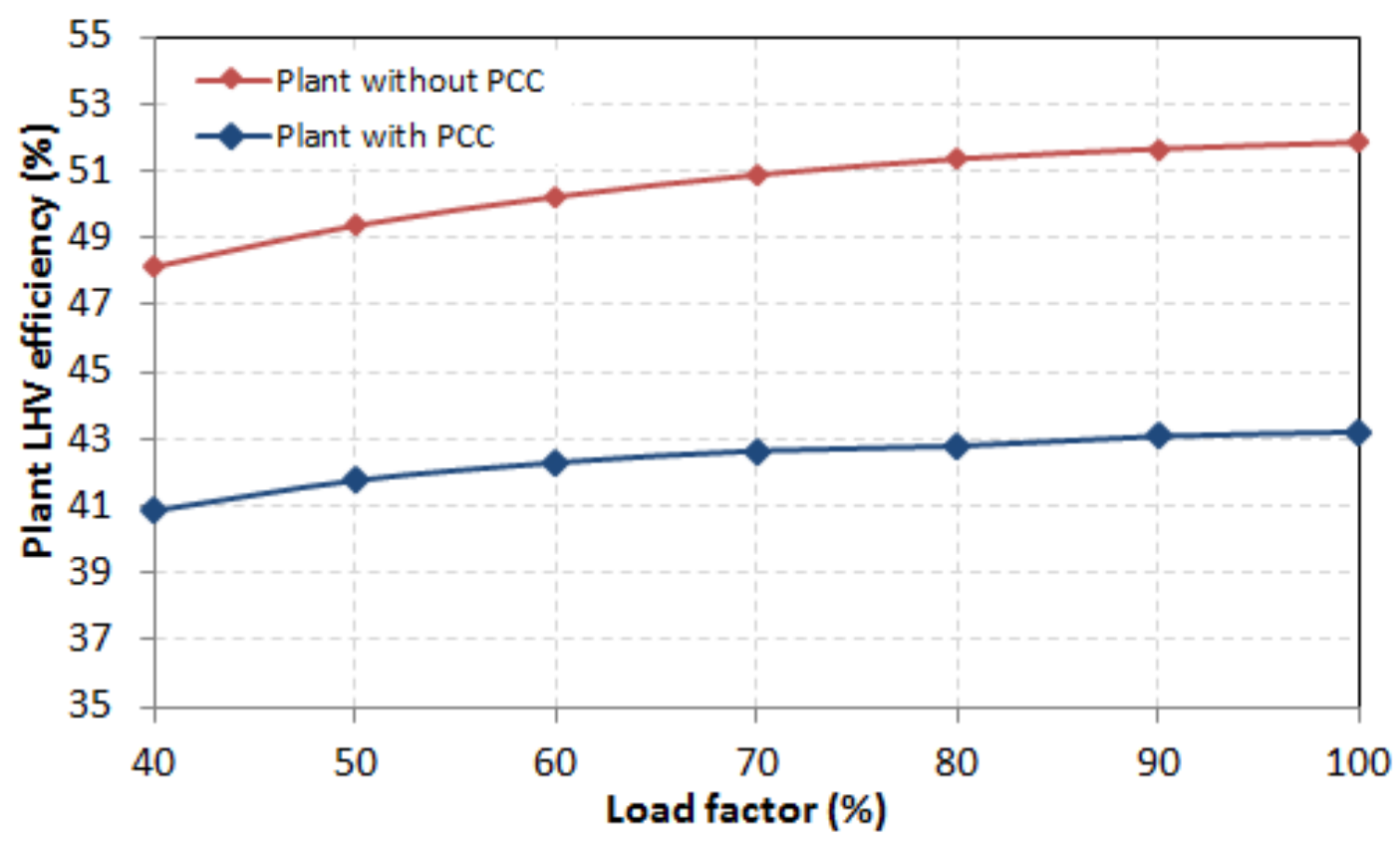

Figure 15: Net plant LHV efficiency with and without PCC

The application of PCC caused the net plant efficiency to drop by $8.64 \%$ points at full-load. This value agrees with the $6.2-9.6 \%$ point drop in net plant efficiency resulting from the implementation of PCC as found in nine studies previous studies (Jordal et al., 2012 and Lindqvist et al., 2014). The reduced impact of PCC at lower load factors was again evident as the net plant efficiency penalty dropped to $7.93 \%$ points at $60 \%$ load.

\subsubsection{Contributions to the Gross Power Output}

The power generated by the CCGT arises from the gas turbine and the LP, IP and HP steam turbines. Table 9 and Figure 16 show the percentage contributions of the gas and steam turbines in the case without CCS.

Table 9: Contributions of the turbines to the gross power output (no PCC)

\begin{tabular}{ccccc}
\hline \multirow{2}{*}{ Load factor (\%) } & \multicolumn{3}{c}{ Contribution to gross plant output (\%) } \\
\cline { 2 - 5 } & Gas turbine & HP steam turbine & IP steam turbine & LP steam turbine \\
\hline 100 & 79.337 & 4.081 & 7.884 & 8.698 \\
90 & 78.511 & 4.254 & 8.091 & 9.144 \\
80 & 77.869 & 4.370 & 8.198 & 9.563 \\
70 & 77.393 & 4.432 & 8.269 & 9.905 \\
60 & 77.031 & 4.416 & 8.300 & 10.253 \\
50 & 76.778 & 4.274 & 8.249 & 10.699 \\
40 & 76.714 & 3.941 & 7.980 & 11.365 \\
\hline
\end{tabular}




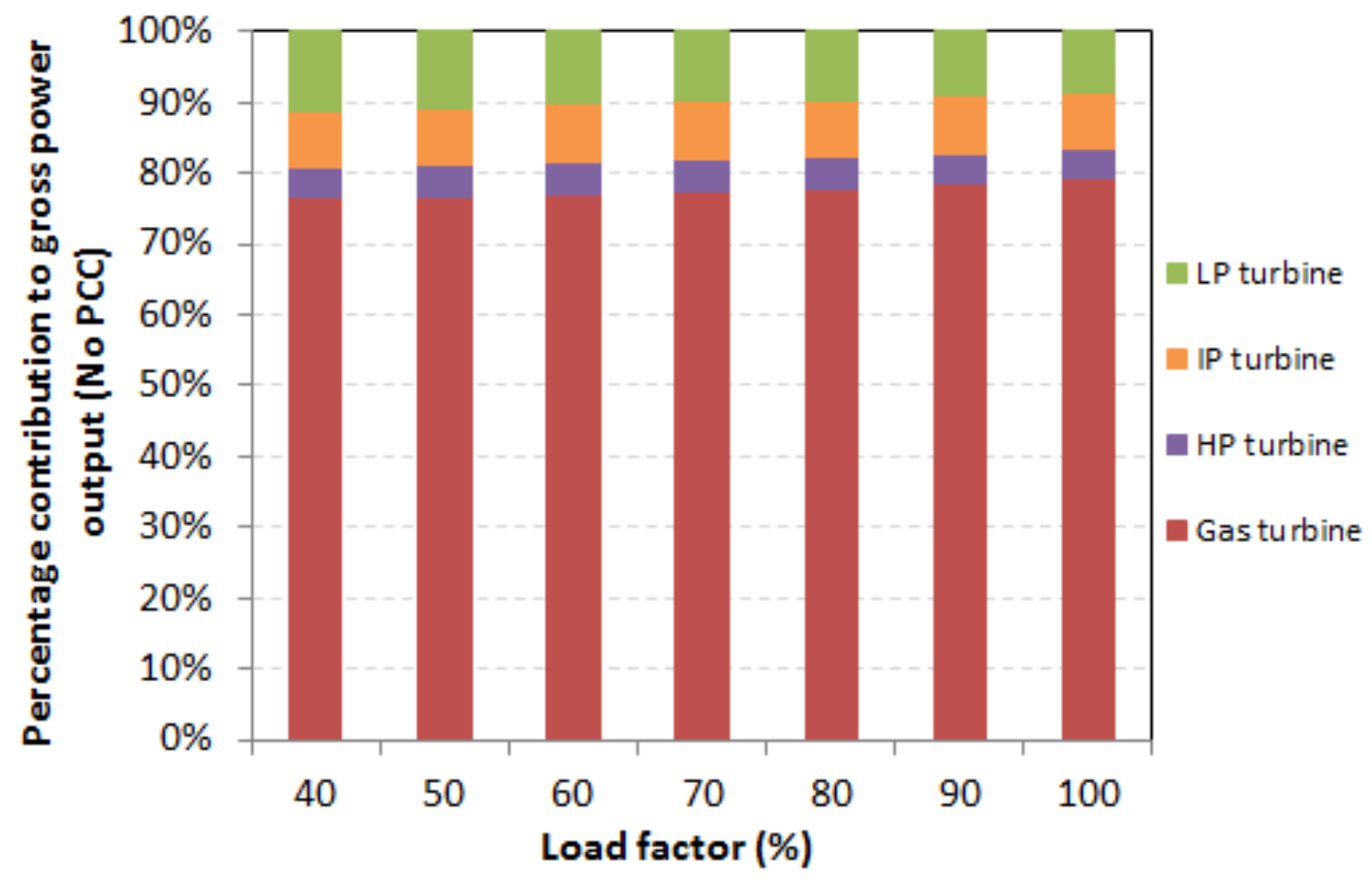

Figure 16: Contributions of the turbines to the gross power output (no PCC)

The gas turbine provides the bulk of the CCGT's power output regardless of whether PCC is implemented or not. The LP turbine contributes $8.70 \%$ to the standalone CCGT's gross power output at full-load but this contribution drops significantly to $1.50 \%$ when PCC is implemented due to the large amount of steam extracted to provide the reboiler duty. This is a key factor in CCGT plants suffering a lower efficiency penalty than an equivalent coal-fired power plant on addition of post-combustion CCS - the coal plants generate a much greater fraction of their overall power from their LP turbine. Table 10 and Figure 17 show the percentage contributions of these units in the case with PCC.

Table 10: Contributions of the turbines to the gross power output (with PCC)

\begin{tabular}{ccccc}
\hline \multirow{2}{*}{ Load factor (\%) } & \multicolumn{4}{c}{ Contribution to gross plant output (\%) } \\
\cline { 2 - 5 } & Gas turbine & HP steam turbine & IP steam turbine & LP steam turbine \\
\hline 100 & 84.282 & 4.870 & 9.351 & 1.496 \\
90 & 83.489 & 5.004 & 9.463 & 2.045 \\
80 & 82.827 & 5.106 & 9.525 & 2.542 \\
70 & 81.932 & 5.161 & 9.569 & 3.337 \\
60 & 81.164 & 5.132 & 9.577 & 4.127 \\
50 & 80.459 & 4.966 & 9.502 & 5.073 \\
40 & 79.927 & 4.587 & 9.191 & 6.295 \\
\hline
\end{tabular}




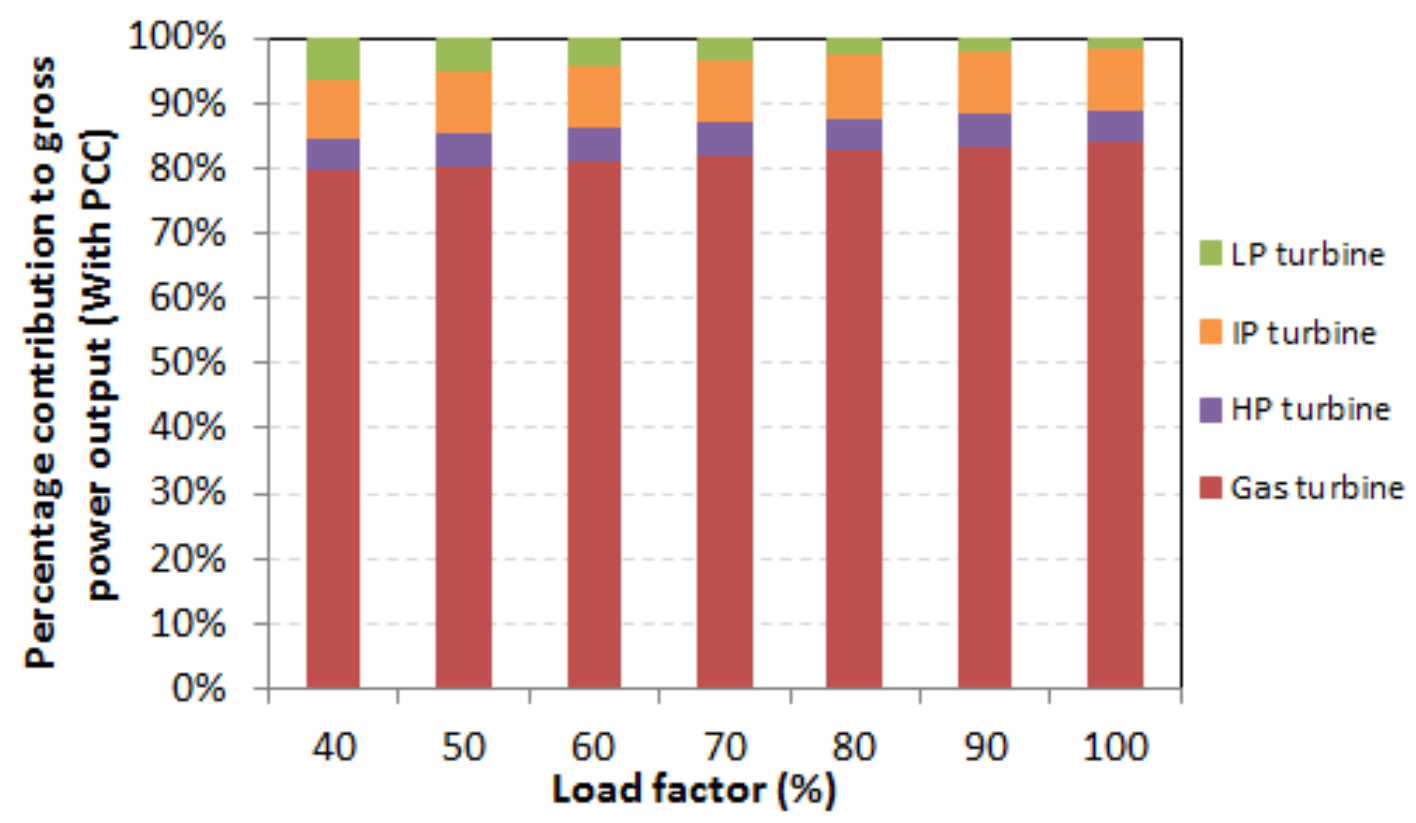

Figure 17: Contributions of the turbines to the gross power output (with PCC)

\subsubsection{Contributions to the PCC energy penalty}

When PCC is implemented, energy is lost because steam is diverted from the LP steam turbine to provide the required for solvent regeneration. Further, and some of the electricity generated by the CCGT must be used to drive the five $\mathrm{CO}_{2}$ compressors, the flue gas blower and the equipment needed to provide cooling water to the flue gas cooler, the trim cooler in the steam extraction scheme, the trim cooler in the capture plant and to the intercoolers in the compression train. The percentage contributions of these units to the total energy penalty imposed when the CCGT is integrated with the PCC plant are shown in Table 11 and Figure 18.

Table 11: Contributions of the PCC plant units to the energy penalty

\begin{tabular}{ccccc}
\hline \multirow{2}{*}{$\begin{array}{c}\text { Load factor } \\
\text { (\%) }\end{array}$} & \multicolumn{3}{c}{ Percentage contribution to energy penalty (\%) } \\
\cline { 2 - 5 } & Reboiler & CO $_{2}$ Compressors & $\begin{array}{c}\text { Trim cooler (Capture } \\
\text { Plant) }\end{array}$ & Miscellaneous \\
\hline 100 & 74.309 & 18.891 & 5.642 & 1.158 \\
90 & 74.108 & 19.138 & 5.598 & 1.156 \\
80 & 73.786 & 19.477 & 5.579 & 1.159 \\
70 & 73.033 & 20.162 & 5.604 & 1.201 \\
60 & 72.079 & 21.005 & 5.657 & 1.259 \\
50 & 70.913 & 22.029 & 5.720 & 1.338 \\
40 & 69.514 & 23.260 & 5.779 & 1.447 \\
\hline
\end{tabular}




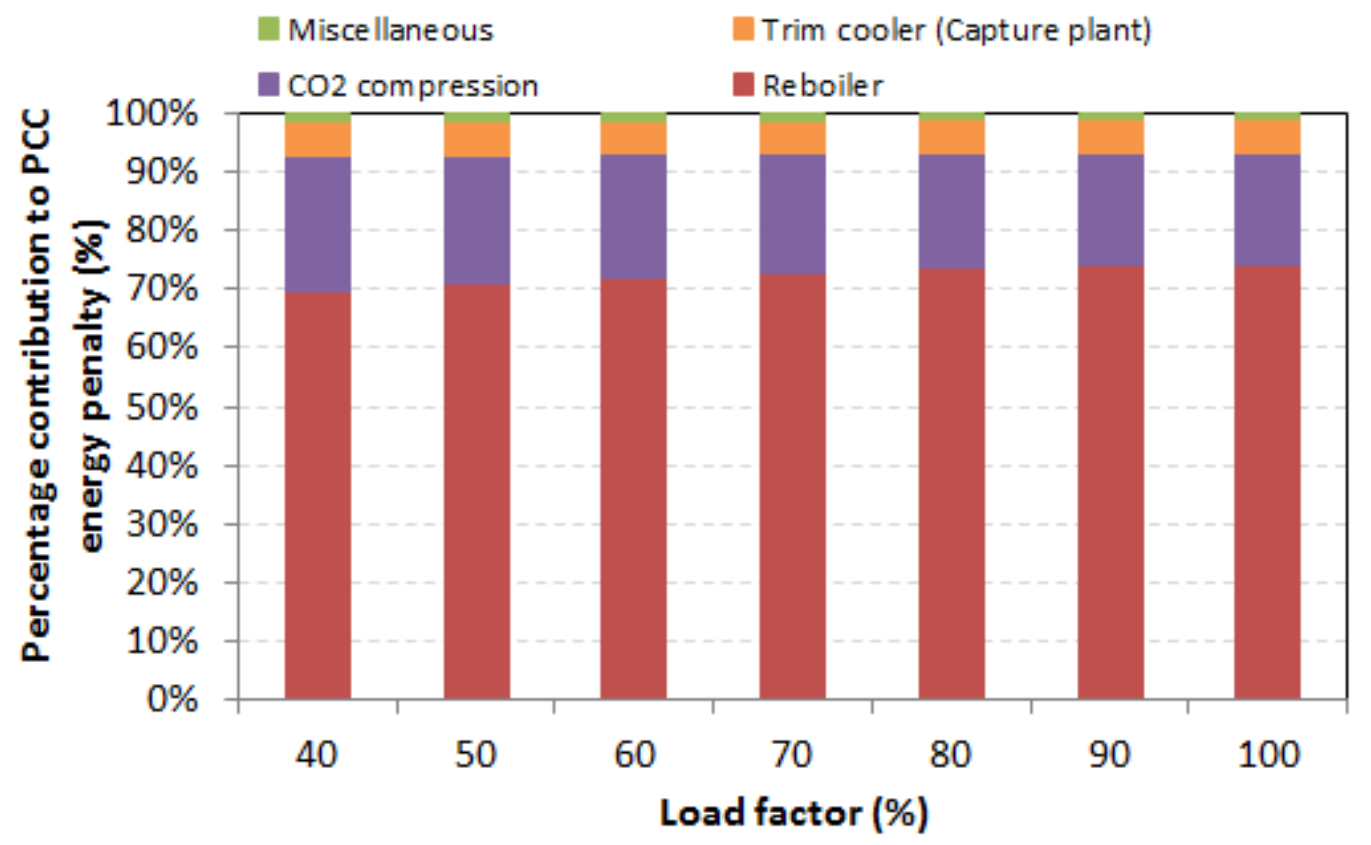

Figure 18: Contribution of the PCC plant units to the energy penalty

At full-load, the extraction of steam from the IP/LP cross-over to provide the reboiler duty accounts for $74.31 \%$ of the energy penalty, the electricity required to run the $\mathrm{CO}_{2}$ compressors accounts for $18.89 \%$, the trim cooler in the PCC plant constitutes $5.64 \%$ and the remaining units are grouped as miscellaneous equipment and account for $1.16 \%$. It is interesting to note that the energy penalty associated with operating the compressors increases at part load to $23.26 \%$ of the total energy penalty, whilst that associated with solvent regeneration reduces to $69.5 \%$. The power requirement associated with operating the trim cooler in the PCC plant is relatively large. This arose from the fact that the cooling water was set to have a $5 \mathrm{~K}$ temperature rise in the gPROMS model and this resulted in a required cooling water flowrate of approximately $8,000 \mathrm{~kg} \mathrm{~s}^{-1}$.

\subsubsection{Reboiler Duty and Steam Extraction Rate}

The reboiler's (heat) duty decreases linearly with decreasing load factor as the total steam extracted from the IP/LP cross-over decreases more-or-less linearly with load factor as shown in Figure 19. Figure 19 also shows that the amount of steam extracted as a percentage of the total water flow rate in the steam cycle also decreases in a roughly linear manner with load factor. At full-load $85.25 \%$ of the total steam flow is extracted whilst at $40 \%$ load this figure is $51.17 \%$. This factor is responsible for the observed reduction in the energy penalty at lower loads. 


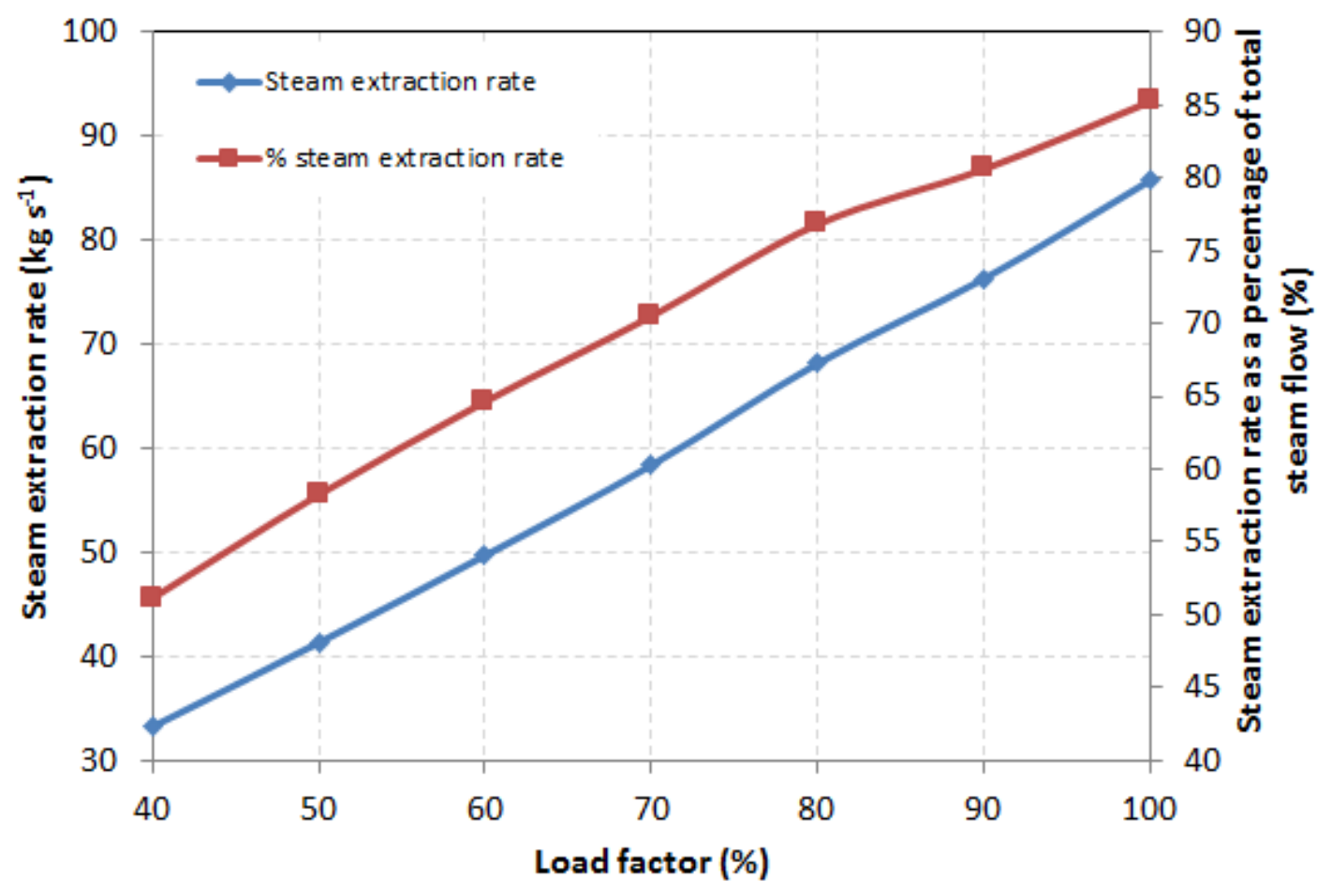

Figure 19: Steam extraction rate from the IP/LP cross-over and the amount of steam extracted as a percentage of the total steam flow in steam cycle

\subsection{Plant Economics}

Carbon capture and storage is expected to see deployment to the UK's energy system in the 2030 - 2040's (Mac Dowell \& Staffell, 2016). We therefore examine the impact that applying PCC to the $420 \mathrm{MW}$ CCGT has on the cost of electricity generated when considering the natural gas prices predicted by DECC for the 2030s. A break-down of the total levelised cost of electricity (LCOE) is presented and the $\mathrm{CO}_{2}$ tax rate that will be needed to make the LCOE of the plant without CCS equal to that of the plant with CCS is also calculated.

\subsubsection{Levelised Cost of Electricity with and without PCC}

The graph in Figure 20 shows the LCOE for the two power generation cases (with and without PCC) over the plant's operating range. The LCOE values predicted will be lower than what they would be in reality because the calculations that were used do not include $\mathrm{CO}_{2}$ taxes, site operating taxes, maintenance costs, labour costs, etc. Applying PCC caused the LCOE from the CCGT to increase by $34.7 \%$ (from £38/MWh to £51/MWh), 29.6\% (from $£ 58 / \mathrm{MWh}$ to $£ 75 / \mathrm{MWh}$ ) and $27.1 \%$ (from $£ 78 / \mathrm{MWh}$ to $£ 100 / \mathrm{MWh}$ ) under low, central and high natural gas price predictions respectively when operating at full load.

The UK's Department of Energy and Climate Change (DECC) predicts that the LCOE from a CCGT commissioned in 2030 will increase by $20.9 \%$, from $£ 86 / \mathrm{MWh}$ to $£ 104 / \mathrm{MWh}$ following implementation of PCC, under central capital cost predictions (DECC, 2013). We note that our results are in good agreement with those of DECC. Further, these results also show good agreement with the recent work of Canepa and Wang (Canepa \& Wang, 2015).

It is clear that changes in the price of natural gas have a very significant impact on both the short run marginal cost (SRMC) and LCOE of CCS applied to CCGT power stations. An increase in natural gas prices of $£ 1 / G J$ will cause the LCOE in the CCGT without PCC to increase by $£ 6.94 / \mathrm{MWh}$ and by $£ 8.33 / \mathrm{MWh}$ in the case with PCC. The LCOE also increased 
marginally in both cases as the plant is ramped down due to the decrease in the plant's efficiency.

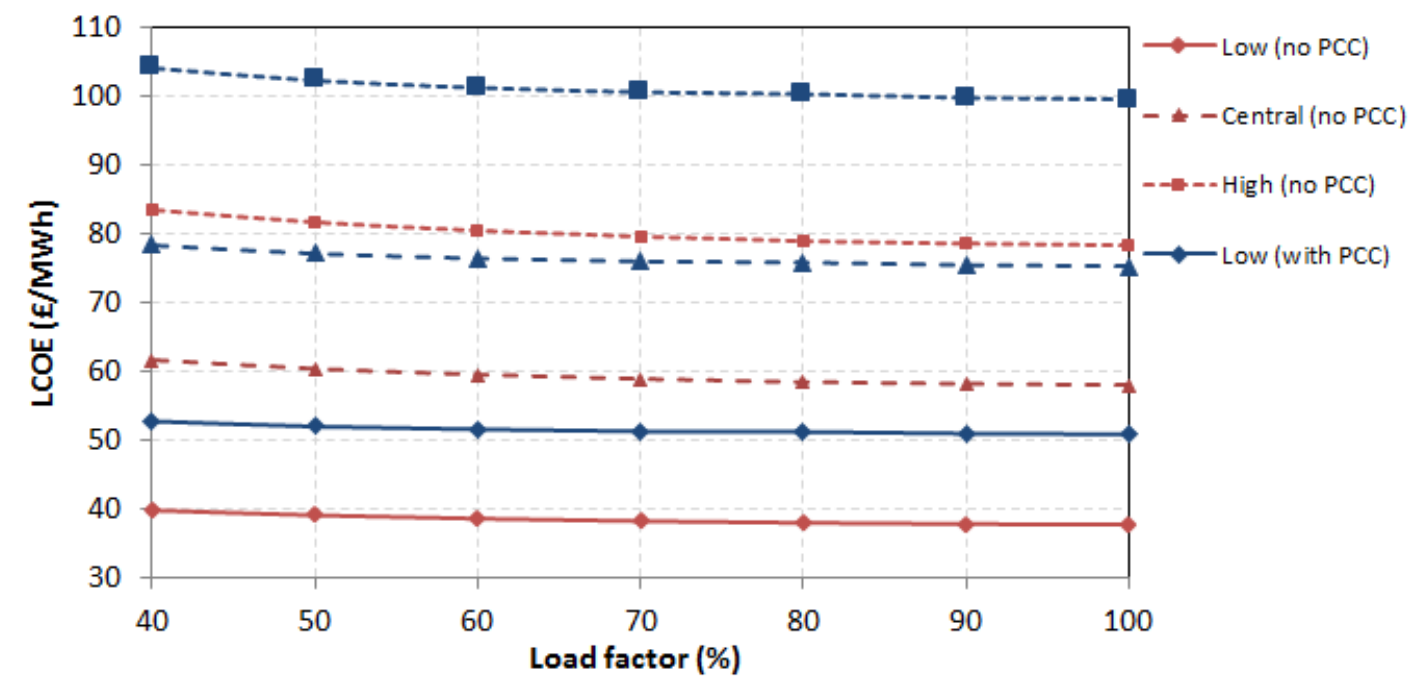

Figure 20: Levelised cost of electricity from the 420MW CCGT model with and without PCC

\subsubsection{Contributions to the Levelised Cost of Electricity}

A break-down of the LCOE from the two CCGT cases (with and without PCC) under central natural gas price predictions can be seen in Figure 21 and in Figure 22. Fuel costs contribute approximately $82 \%$ of the LCOE in the case without PCC and $76 \%$ in the case with PCC.

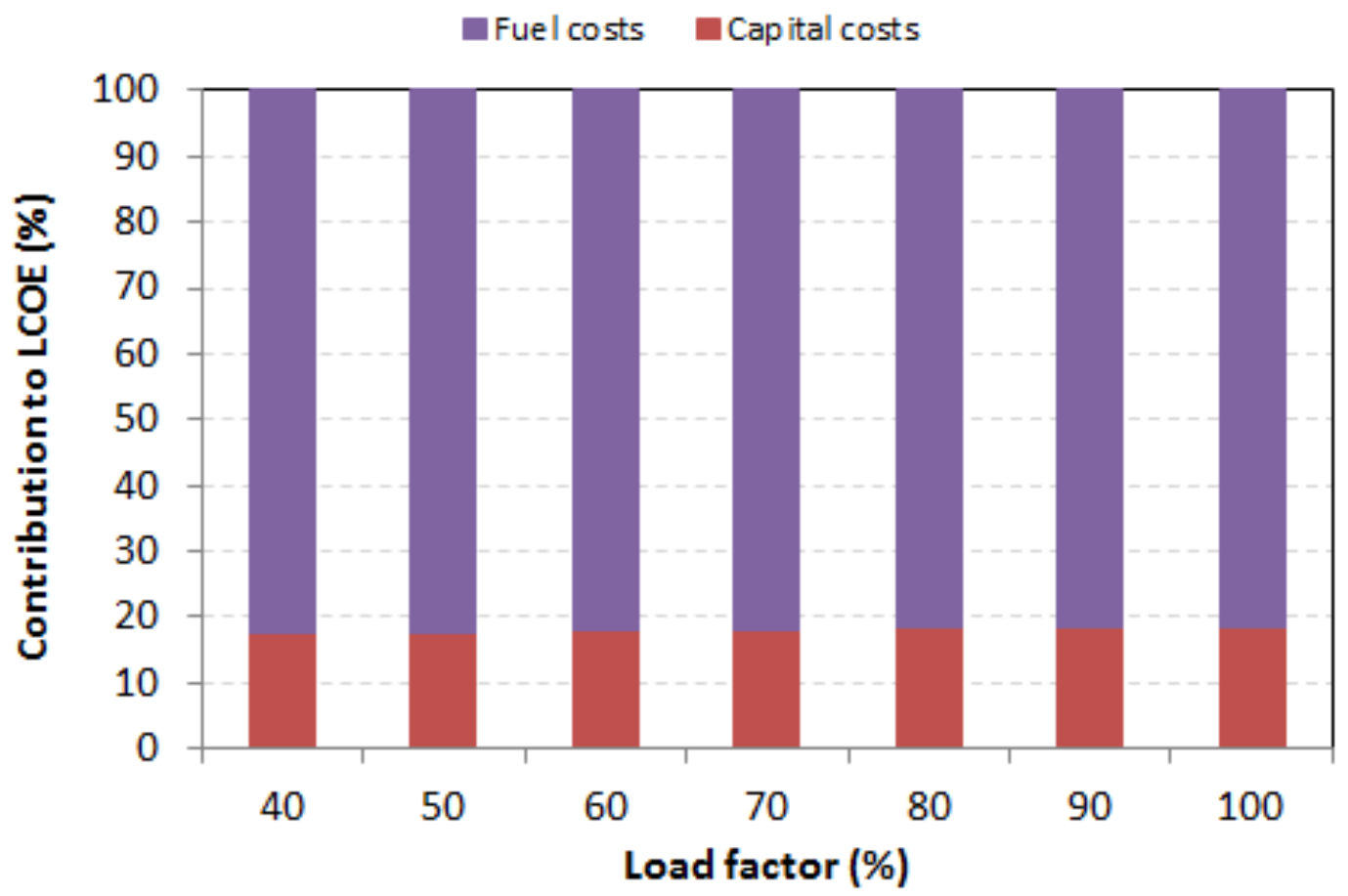

Figure 21: Contributions to the LCOE from the CCGT without PCC under central natural gas price predictions

The costs of transporting the captured $\mathrm{CO}_{2}$ via pipeline and storing it in an appropriate geological reservoir account for approximately $2.6 \%$ of the total LCOE from the CCGT with PCC. Another interesting observation is that the proportions of the various contributions remain more or less constant across the range of plant loads evaluated in this study. 


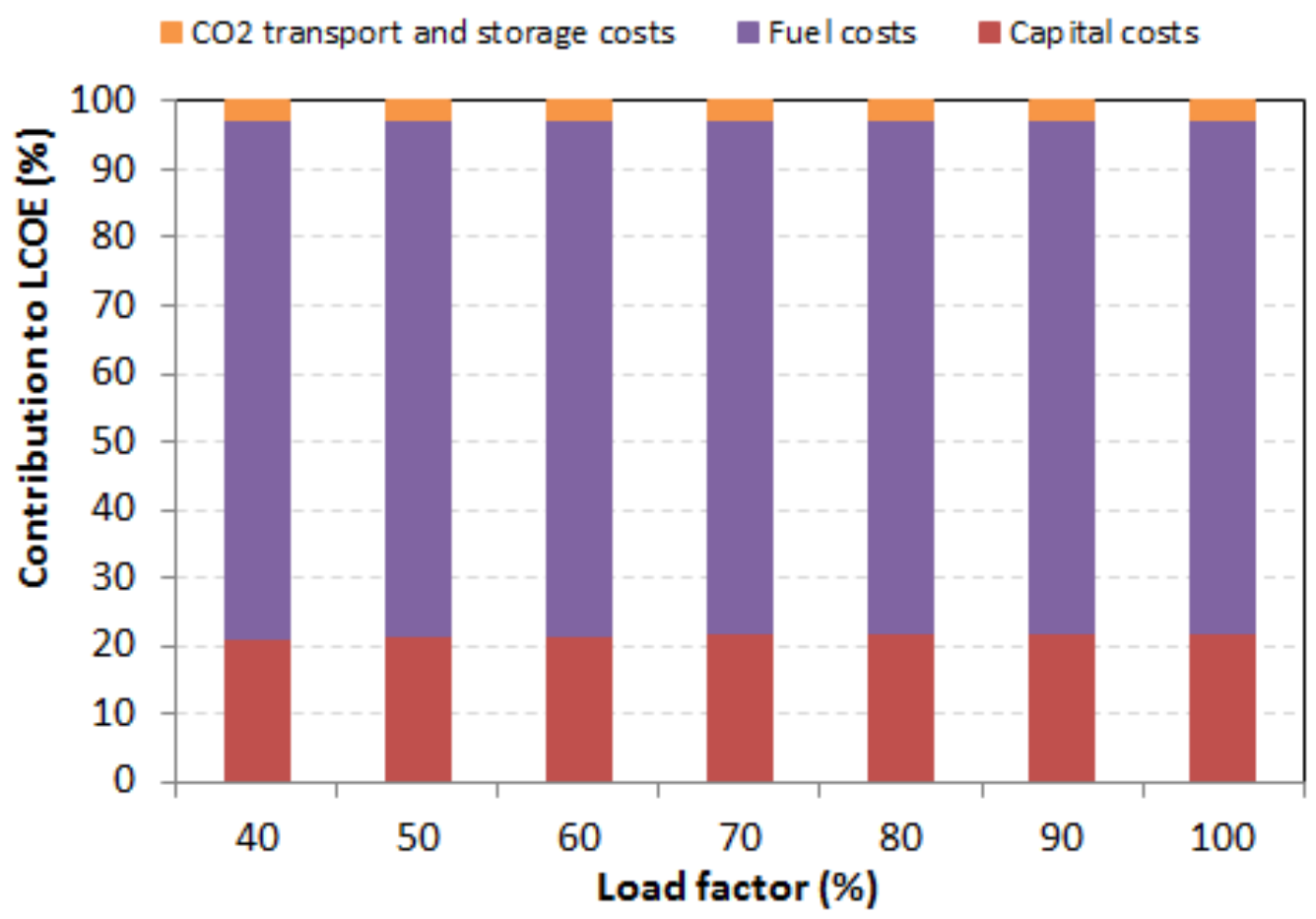

Figure 22: Contributions to the LCOE from the CCGT with PCC under central natural gas price predictions

\subsubsection{Cost of $\mathrm{CO}_{2}$ avoided}

The cost of $\mathrm{CO}_{2}$ avoided is strongly influenced by the price of natural gas but is relatively weakly influenced by the plant's load factor as can be seen in Figure 23. This is primarily driven by the relatively small capital intensity of CCGTs relative to other forms of power plants, for example, coal-fired power plants. The $\mathrm{CO}_{2}$ tax rate will need to be $£ 59 /$ tonne $\mathrm{CO}_{2}$, $£ 48$ /tonne $\mathrm{CO}_{2}$ and $£ 36.50$ /tonne $\mathrm{CO}_{2}$ under high, central and low natural gas price predictions respectively. These calculated values are higher than the penalty of $£ 27 /$ tonne $\mathrm{CO}_{2}$ that was proposed by the International Energy Agency to cover the costs of CCS (Hammond, Akwe \& Williams, 2011).

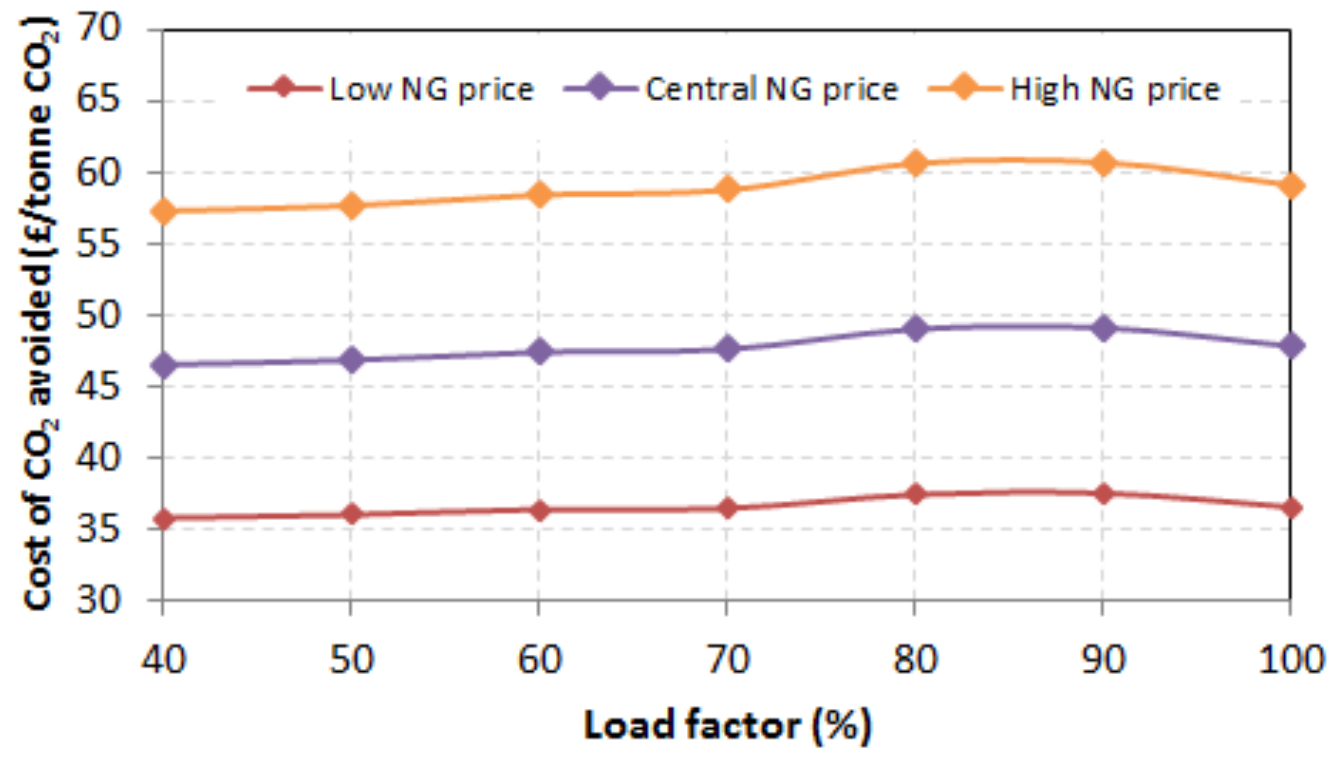

Figure 23: Cost of $\mathrm{CO}_{2}$ avoided under low, central and high natural gas price predictions 
Figure 23 shows that the cost of $\mathrm{CO}_{2}$ avoided increases at load factors of $80 \%$ and $90 \%$. This is an anomaly caused by fluctuations in the $\mathrm{CO}_{2}$ capture efficiency in the capture plant model.

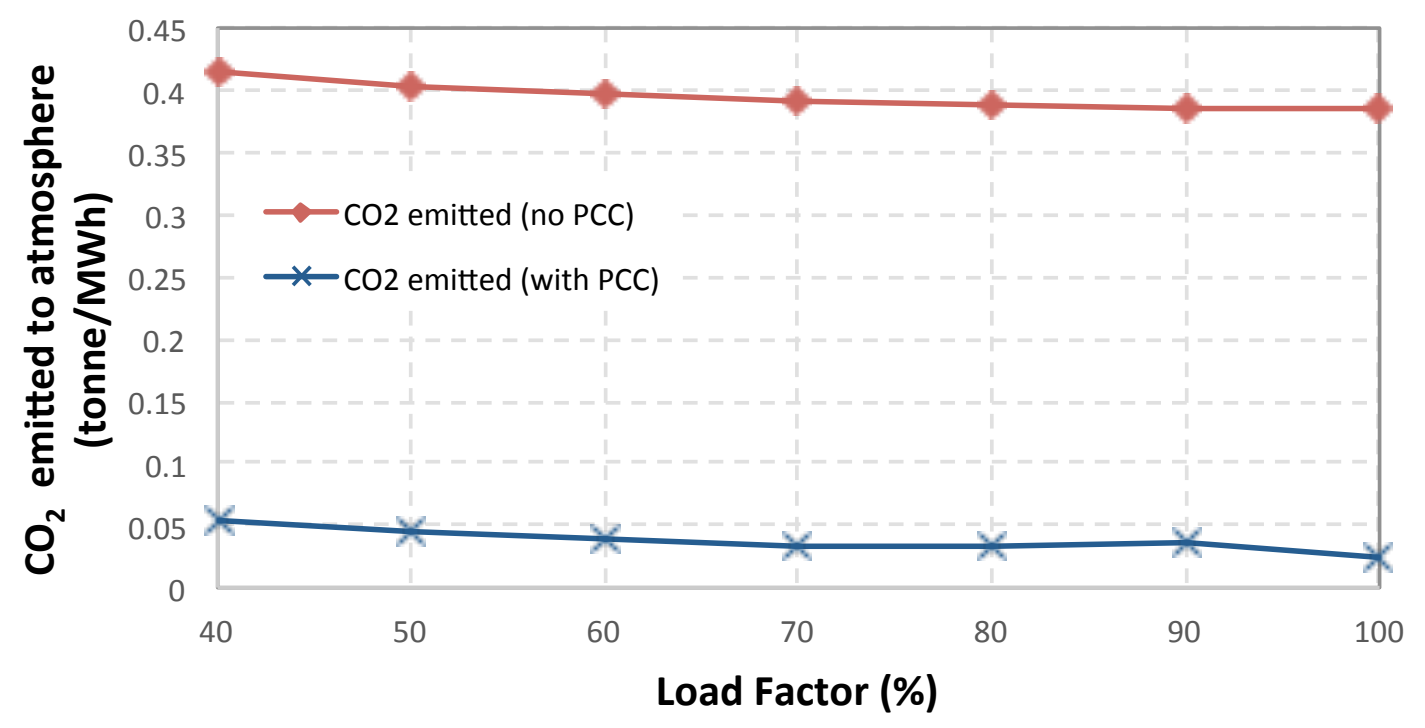

Figure 24: Rates of $\mathrm{CO}_{2}$ emitted by the CCGT plant with and without PCC respectively

The effect of the fluctuations in the $\mathrm{CO}_{2}$ capture efficiency is illustrated in Figure 24, which show graphs of the $\mathrm{CO}_{2}$ emitted to the atmosphere and captured in the two power plant scenarios. The slightly non-monotonic behaviour that is observed in Figure 24 is an artefact of the $\mathrm{CO}_{2}$ capture plant model. The CCS plant dynamics lag those of the steady state CCGT model as the system is ramped from full to part load. This leads to a surplus of solvent in the capture plant between load factors of $75-95 \%$. Once the power plant is ramped below $75 \%$ of nameplate capacity, the solvent circulation rate in the $\mathrm{CO}_{2}$ capture plant has also reduced, and therefore responds in line with the power plant perturbations. Further, Figure 24 quite conclusively shows that, in the absence of CCS, gas-fired power plants cannot be considered to be low carbon.

\section{Conclusions}

We have presented a detailed mathematical model of a triple-pressure CCGT power station integrated with an amine-based post-combustion $\mathrm{CO}_{2}$ capture process and subsequent multistage $\mathrm{CO}_{2}$ compression train. We have validated the performance of the CCGT model by comparison with the commercial Thermoflow THERMOFLEX simulation package and observed that our model accurately reproduces the performance of the commercial simulator over a range of full- and part-load conditions. We have found that our model reproduces the net power output and efficiency of the Thermoflow model to within $4.1 \%$ and the full load temperature profile within the HRSG to within $2.9 \%$. Performance suffers at load factors less than $50 \%$ owing to increasing phase change in the heat exchangers and a lack of detail in the compressor, gas turbine and steam turbine sub-models. However, as CCGTs might be expected to operate between $50-100 \%$ load under normal operation, with operation below $50 \%$ of nameplate capacity as part of a shut-down operation, this model is deemed appropriate for simulation of normal operation. This is of particular importance as CCGT power stations, with and without CCS will increasingly be required to operate in a highly flexible and load following manner, in sympathy with the availability of intermittent renewable energy sources.

In integrating the CCGT and $\mathrm{CO}_{2}$ capture process, steam for the solvent reboiler was extracted from the IP-LP crossover point. Here, it was first necessary to de-superheat this steam, and whilst this heat was subsequently recovered and added to the condensate train, it follows that it may be preferable to extract steam from an inter-stage bleed within the LP turbine, rather than prior to the turbine. This would have the benefit of reducing the efficiency penalty associated with the operation of the $\mathrm{CO}_{2}$ capture process. 
One of the primary challenges associated with the application of post-combustion CCS to CCGTs is the dilute nature of the exhaust gas. To mitigate against this, we evaluated the ability of exhaust gas recycle (EGR) to increase the concentration of $\mathrm{CO}_{2}$. We found that the $\mathrm{CO}_{2}$ concentration varied between $3-5 \mathrm{~mol} \%$ as a function of load factor in the range $40-$ $100 \%$ in the absence of EGR, but with EGR it was possible to increase the concentration of the $\mathrm{CO}_{2}$ to between $6-9 \mathrm{~mol} \%$. An important side-effect of EGR was also to reduce the $\mathrm{O}_{2}$ concentration in the exhaust gas from approximately $20-21 \mathrm{~mol} \%$ to $13-15 \mathrm{~mol} \%$, which may be important in contributing to a reduction in solvent degradation. However, the requirement for greater than $16 \mathrm{~mol} \% \mathrm{O}_{2}$ in the combustion chamber acts to limit the amount of EGR as a function of load factor - increasing from $33.65 \%$ at $100 \%$ load factor to $40.4 \%$ at $40 \%$ load factor.

We simulated the dynamic behaviour of the integrated power-capture plant, and noted that the relaxation times of the individual units within this system mean that the is a non-negligible delay for the system to reach a steady state after each simulation. A key area of future work will be to include the individual dynamics of the sub-units within the CCGT model. The calculated net efficiency of the integrated power-capture plant was observed to be in excellent agreement with similar studies in the literature for both full and part load scenarios.

An evaluation of the LCOE associated with our model was also found to be in good agreement with literature values. Importantly, it was observed that whilst the absolute costs and efficiency of the CCGT-CCS varied appreciably as a function of power plant load factor, the cost structure did not. The implication is that once an optimal process configuration and operating strategy has been determined, it will not be necessary to revisit this for the actual dispatch profiles that are likely to be experienced by plants operating in a real energy system.

Taken together, this gives us confidence that this tool is suitable for use in a range of design and systems modelling purposes. Importantly, the general trend that sustained off-design point operation will have the effect of increasing the LCOE of these plants implies that energy systems should aim to maximise their utilisation of CCS assets wherever possible. However, it is important to note that a simple metric such as LCOE does not accurately reflect value provided to a decarbonised energy system by a dispatchable, low carbon power station such as a decarbonised CCGT power plant.

It was interesting to note that the energy cost associated with operating the compression train became relatively greater under part-load scenarios in contrast to the relative reduction in cost associated with solvent regeneration. Given that CCS-CCGTs are expected to be required to operate in part load with increasing frequency, the identification of improved designs and operating procedures under realistic conditions is of increasing importance. Simply recycling $\mathrm{CO}_{2}$ in the same manner as EGR for increasing the concentration of $\mathrm{CO}_{2}$ is unlikely to be an optimal solution. It will also be necessary to operate this aspect of the process such that the impact on the reliable and safe operation of the transport and sequestration elements of the CCS chain is minimised.

Owing to reduced efficiency under off-design point operation, the carbon intensity of the decarbonised CCGT increased. Thus, in order to ensure that CCS-CCGTs actually provide reliably low carbon power, it may be necessary to increase the fraction of $\mathrm{CO}_{2}$ that is removed at part-load conditions to greater to $95 \%$ under part-load conditions. A key implication is that this would serve to increase both the average levelised and short run marginal cost of gasCCS power plants, potentially further reducing access to the electricity market. This serves to emphasise the importance of identifying reduced cost approaches for delivering gas-CCS designs and operating procedures optimised for part load. However, it is also noted that the cost of gas-CCS is a strong function of the prevailing gas price. In this context, the increasing fungibility of the gas market may serve to reduce gas prices, which, in turn, could reduce the cost of gas-CCS.

\section{Acknowledgements}

The authors thank the Engineering and Physical Sciences Research Council (EPSRC) of the UK (Grant number: EP/M001369/1) for funding required to carry out this work. 


\section{References}

Alhajaj, A., Mac Dowell, N. \& Shah, N. (2016) A techno-economic analysis of postcombustion $\mathrm{CO}_{2}$ capture and compression applied to a combined cycle gas turbine: Part I. A parametric study of the key technical performance indicators. International Journal of Greenhouse Gas Control. 44, 26-41.

Amrollahi, Z., Ertesvag, I.S. \& Bolland, O. (2011) Thermodynamic analysis on postcombustion $\mathrm{CO}_{2}$ capture of natural-gas-fired power plant. International Journal of Greenhouse Gas Control. 5, 422-426.

Benato, A., Stoppato, A. \& Mirandola, A. (2015) Dynamic behaviour analysis of a three pressure level heat recovery steam generator during transient operation. Energy. 90(2), 15951605.

Boot-handford, M., Abanades, J. C., Anthony, E. J., Blunt, M. J., Brandani, S., Mac Dowell, N., Fernndez, J. R., Ferrari, M., Gross, R., Hallett, J. P., Haszeldine, R. S., Heptonstall, P., Lyngfelt, A., Makuch, Z., Mangano, E., Porter, R. T. J., Pourkashanian, M., Rochelle, G. T., Shah, N., Yao, J. G. \& Fennell, P. S. (2013) Carbon capture and storage update. Energy \& Environmental Science. 7(1), 130-189.

Campanari, S., Chiesa, P., Manzolini, G. \& Bedogni, S. (2014) Economic analysis of CO2 capture from natural gas combined cycles using Molten Carbonate Fuel Cells. Applied Energy. 130, 562-573.

Canepa, R. \& Wang, M. (2015) Techno-economic analysis of a $\mathrm{CO}_{2}$ capture plant integrated with a commercial scale combined cycle gas turbine (CCGT) power plant. Applied Thermal Engineering. 74, 10-19.

Canepa, R., Wang, M., Biliyok, C. \& Satta, A. (2013) Thermodynamic analysis of combined cycle gas turbine power plant with post-combustion $\mathrm{CO}_{2}$ capture and exhaust gas recirculation. Proceedings of the Institution of Mechanical Engineers, Part E: Journal of Process Mechanical Engineering. 227, 89- 105.

Ceccarelli, N., van Leeuwen, M., Wolf, T., van Leeuwen, P., van der Vaart, R., Maasa, W. \& Ramos, A. (2014) Flexibility of low-CO2 gas power plants: Integration of the CO2 capture unit with CCGT operation. Energy Procedia. 63, 1703-1726.

Çengel, Y.A. (2007) Thermodynamics: an engineering approach. 6th edition. New York; London, McGraw-Hill. pp. 517-530, 567-589.

Cormos, A.M. \& Simon, A. (2013) Dynamic Modelling of $\mathrm{CO}_{2}$ Capture by Calcium-Looping Cycle. Chemical Engineering Transactions. 35, 421-426.

Cormos, C.C., Vatopoulos, K. \& Tzimas, E. (2013) Assessment of the consumption of water and construction materials in state-of-the-art fossil fuel power generation technologies involving CO2 capture. Energy. 51, 37-49.

DECC. (2013) Electricity Generation Costs (December 2013) Department of Energy and Climate Change. pp. 25.

Dechamps, P. J., Pirard, N. \& Mathieu, P. (1995) Part-load operation of combined-cycle plants with and without supplementary firing. Journal of Engineering for Gas Turbines and Power. 117 (3), 475-483.

Dillon, D., Grace, D., Maxson, A., Børter, K., Augeli, J., Woodhouse, S. \& Aspelund, G. (2013) Post-combustion capture on natural gas combined cycle plants: A technical and Economical evaluation of retrofit, new build and the application of exhaust gas recycle. Energy Procedia. 37, 2397-2405. 
Duan, H.B., Fan, Y. \& Zhu, L. (2012) What's the most cost-effective policy of CO2 targeted reduction: An application of aggregated economic technological model with CCS? Applied Energy. 112, 868-875.

Ehyaei, M.A., Tahani, M., Ahmadi, P. \& Esfandiari, M. (2015) Optimization of fog inlet air cooling system for combined cycle power plants using genetic algorithm. Applied Thermal Engineering. 76, 449-461.

ElKady, A.M., Evulet, A., Brand, A., Ursin T.P. \& Lynghjem, A. (2009) Application of exhaust gas recirculation in a DLN F-Class combustion system for post-combustion carbon capture. Journal of Engineering for Gas Turbines and Power. 131(3), 034505 - 034511.

Flø, N.E., Kvamsdal, H.M. \& Hillestad, M. (2016) Dynamic simulation of post-combustion $\mathrm{CO}_{2}$ capture for flexible operation of the Brindisi pilot plant. International Journal of Greenhouse Gas Control. Article in press.

Galindo A., Davies L.A., Gil-Villegas A. \& Jackson G. (1998) The thermodynamics of mixtures and the corresponding mixing rules in the SAFT-VR approach for potentials of variable range. Molecular Physics. 93(2), 241-252.

Gerbelová, H., Versteeg, P., loakimidis, C.S. \& Ferrão, P. (2013) The effect of retrofitting Portuguese fossil fuel power plants with CCS. Applied Energy. 101, 280-287.

Gil-Villegas A., Galindo A., Whitehead P.J., Mills S.J., Jackson G. \& Burgess A.N. (1997) Statistical associating fluid theory for chain molecules with attractive potentials of variable range. The Journal of Chemical Physics. 106, 4168-4186.

Goto, K., Yogo, K. \& Higashii, T. (2013) A review of efficiency penalty in a coal-fired power plant with post-combustion CO2 capture. Applied Energy. 111, 710-720.

Hammond, G. P., Akwe, S. S. O. \& Williams, S. (2011) Techno- economic appraisal of fossilfuelled power generation systems with carbon dioxide capture and storage. Energy. 36 (2), 975-984.

Hemmer, F. \& Klassen, E. (2012) Internation Comparison of Fossil Power Efficiency and $\mathrm{CO}_{2}$ Intensity. ECOFYS.

Herraiz, L., Hogg, D., Cooper, J., Gibbins, J. \& Lucquiaud (2015) Reducing water usage with rotary regenerative gas/gas heat exchangers in natural gas-fired power plants with postcombustion carbon capture. Energy. 90, 1994-2005.

Horlock, J. H. (2003) Advanced gas turbine cycles. Amsterdam ; London, Elsevier.

Intergovernmental Panel on Climate Change. (2013) Climate Change 2013: The Physical Science Basis. New York, USA, Cambridge University Press.

Johnsson, F., Odenberger, M. \& Göransson, L. (2014) Challenges to integrate CCS into low carbon electricity markets. Energy Procedia. 63, 7485-7493.

Jonshagen, K., Sipöcz, N. \& Genrup, M. (2010) Optimal combined cycle for CO2 capture with EGR. In: Proceedings of the ASME turbo expo, Glasgow, UK, 14-18 June 2010. New York, ASME. GT2010-23420, 867-875.

Jordal, K., Ystad, P.A.M., Anantharaman, R., Chikukwa, A. \& Bollan, O. (2012) Design-point and part-load considerations for natural gas combined cycle plants with post combustion capture. International Journal of Greenhouse Gas Control. 11, 271-282.

Kang, C.A., Brandt, A.R. \& Durlofsky, L.J. (2015) A new carbon capture proxy model for optimizing the design and time-varying operation of a coal-natural gas power station. International Journal of Greenhouse Gas Control. Article in press. 
Kuramochi, T., Ramírez, A., Faaij, A. \& Turkenburg, W. (2009) Post-combustion $\mathrm{CO}_{2}$ capture from part-load industrial NGCCCHPs: selected results. Energy Procedia. 1, 1395-1402.

Le Moullec, Y. \& Kanniche, M. (2011) Screening of flowsheet modifications for an efficient monoethanolamine (MEA) based post- combustion $\mathrm{CO}_{2}$ capture. International Journal of Greenhouse Gas Control. 5 (4), 727-740.

Lepaumier, H., Picq, D. \& Carrette, P.L. (2009) New amines for $\mathrm{CO}_{2}$ capture. II. Oxidative degradation mechanisms. Industrial \& Engineering Chemistry Research. 48, 9068-9075.

Li, H., Haugen, G., Ditaranto, M., Berstad, D. \& Jordal, K. (2011) Impacts of exhaust gas recirculation (EGR) on the natural gas combined cycle integrated with chemical absorption $\mathrm{CO}_{2}$ capture technology. Energy Procedia. 4, 1411-1418.

Lindqvist, K., Jordal, K., Haugen, G., Hoff, K.A. \& Anantharaman, R. (2014) Integration aspects of reactive absorption for post-combustion $\mathrm{CO}_{2}$ capture from NGCC (natural gas combined cycle) power plants. Energy. 78, 758-767.

Loud, R.L. \& Slaterpryce, A.A. (1991) Gas turbine inlet air treatment. In: GE Power Generation, GER-3419A.

Mac Dowell, N., Florin, N., Buchard, A., Hallett, J., Galindo, A., Jackson, G., Adjiman, C.S., Williams, C.K., Shah, N. \& Fennell, P. (2010) An overview of $\mathrm{CO}_{2}$ capture technologies. Energy \& Environmental Science. 3(11), 1645-1669.

Mac Dowell N., Galindo A., Jackson G. \& Adjiman C.S. (2010) Integrated solvent and process design for the reactive separation of $\mathrm{CO}_{2}$ from flue gas. Computer Aided Chemical Engineering. 28, 1231-1236.

Mac Dowell N., Llovell F., Adjiman C.S., Jackson G. \& Galindo A (2009) Modeling the fluid phase behaviour of carbon dioxide in aqueous solutions of monoethanolamine using transferable parameters with the SAFT-VR approach. Industrial \& Engineering Chemistry Research. 49(4), 1883-1899.

Mac Dowell N., Pereira F.E., Llovell F., Blas F.J., Adjiman C.S., Jackson G. \& Galindo, A. (2012) Transferable SAFT-VR models for the calculation of the fluid phase equilibria in reactive mixtures of carbon dioxide, water, and $n$-alkylamines in the context of carbon capture. The Journal of Physical Chemistry B. 115(25), 8155-8168.

Mac Dowell, N. \& Shah, N. (2013) Identification of the cost-optimal degree of CO2 capture: An optimisation study using dynamic process models. International Journal of Greenhouse Gas Control. 13, 44-58.

Mac Dowell, N. \& Shah, N. (2014) Optimisation of post-combustion CO2 capture for flexible operation. Energy Procedia. 63, 1525-1535.

Mac Dowell, N. \& Shah, N. (2015) The multi-period optimisation of an amine-based $\mathrm{CO}_{2}$ capture process integrated with a super-critical coal-fired power station for flexible operation. Computers and Chemical Engineering. 74, 169-183.

Mac Dowell, N., Samsatli, N. J. \& Shah, N. (2013) Dynamic modelling and analysis of an amine- based post- combustion $\mathrm{CO}_{2}$ capture absorption column. International Journal of Greenhouse Gas Control. 12, 247-258.

Mac Dowell, N. \& Staffell, I. (2016) The role of flexible CCS in the UK's future energy system. International Journal of Greenhouse Gas Control. (Accepted 2015). 
Mansouri, M.T., Ahmadi, P., Kaviri, A.G., Nazri, M. \& Jaafar, M. (2012) Exergetic and economic evaluation of the effect of HRSG configurations on the performance of combined cycle power plants. Energy Conversion and Management. 58, 47-58.

Merkel, T. C., Wei, X. T., He, Z. J., White, L. S., Wijmans, J. G. \& Baker, R. W. (2013) Selective Exhaust Gas Recycle with Membranes for $\mathrm{CO}_{2}$ Capture from Natural Gas Combined Cycle Power Plants. Industrial \& Engineering Chemistry Research. 52 (3), 11501159.

Mathieu, P. \& Bolland, O. (2013) Comparison of Costs for Natural gas Power Generation with $\mathrm{CO}_{2}$ Capture. Energy Procedia. 37 (0), 2406-2419.

Mertens, J., Lepaumier, H., Desagher, D. \& Thielens, M.L. (2013) Understanding ethanolamine (MEA) and ammonia emissions from amine based post combustion carbon capture: Lessons learned from field tests. International Journal of Greenhouse Gas Control. $13,72-77$.

Middleton, R.S. \& Eccles, J.K. (2013) The complex future of CO2 capture and storage: Variable electricity generation and fossil fuel power. Applied Energy. 108, 66-73.

Moller, B. F., Genrup, M. \& Assadi, M. (2007) On the off- design of a natural gas- fired combined cycle with $\mathrm{CO}_{2}$ capture. Energy. 32 (4), 353-359.

Naghizadeh, R., Vahidi, B. \& Tavakoli, M. R. B. (2011) Estimating the Parameters of Dynamic Model of Drum Type Boilers Using Heat Balance Data as an Educational Procedure. IEEE Transactions on Power Systems. 26 (2), 775-787.

Pan, M., Aziz, F., Li, B., Perry, S., Zhang, N., Bulatov, I. \& Smith, R. (2016) Application of optimal design methodologies in retrofitting natural gas combined cycle power plants with CO2 capture. Applied Energy. 161, 695-706.

Paterson, W. R. (1984) A replacement for the logarithmic mean. Chemical Engineering Science. 39 (11), 1635-1636.

Peeters, A., Faaij, A. \& Turkenburg, W. C. (2007) Techno-economic analysis of natural gas combined cycles with post-combustion $\mathrm{CO}_{2}$ absorption, including a detailed evaluation of the development potential. International Journal of Greenhouse Gas Control. 1 (4), 396-417.

Perry, R. (1997) Physical and Chemical Data. In: Anonymous Perry's Chemical Engineers' Handbook. 6th edition. McGraw Hill. pp. 155.

Pinheiro Pupo Nogueira, L., Frossard Pereira de Lucena, A., Rathmann, R., Rua Rodriguez Rochedo, P., Szklo, A. \& Schaeffer, R. (2014) Will thermal power plants with CCS play a role in Brazil's future electric power generation?. International Journal of Greenhouse Gas Control. 24, 115-123.

Pritchard, P. J. (2011) Fox and McDonald's introduction to fluid mechanics. 8th edition. Hoboken, N.J., Wiley.

Rezazadeh, F., Gale, W.F., Hughes, K.J. \& Pourkashanian, M. (2015) Performance viability of a natural gas fired combined cycle power plant integrated with post-combustion $\mathrm{CO}_{2}$ capture at part-load and temporary non-capture operations. International Journal of Greenhouse Gas Control. 39, 397-406.

Riesz, J., Vithayasrichareon, P. \& MacGill, I. (2015) Assessing "Gas Transition" pathways to low carbon electricity - An Australian case study. Applied Energy. 154, 794-804.

Rodriguez J., Mac Dowell N., Llovell F., Adjiman C.S., Jackson G. \& Galindo A. (2012) Modelling the fluid phase behaviour of aqueous mixtures of multifunctional alkanolamines and 
carbon dioxide using transferable parameters with the SAFT-VR approach. Molecular Physics. 110(11-12), 1325-1348.

Shah, R. K. (2003) Fundamentals of heat exchanger design. New York ; Chichester, John Wiley \& Sons.

Shakerian, F., Kim, K.H. Szulejko, J.E. \& Park, J.W. (2015) A comparative review between amines and ammonia as sorptive media for post-combustion $\mathrm{CO}_{2}$ capture. Applied Energy. $148,10-22$

Sinnott, R. K. (2005) Coulson \& Richardson's chemical engineering. Vol. 6, chemical engineering design. 4th edition. Oxford, Butterworth-Heinemann.

Sipöcz, N., Jonshagen, K., Assadi, M. \& Genrup, M. (2010) Novel High-Performing SinglePressure Combined Cycle With CO2 Capture. Journal of Engineering for Gas Turbines and Power. 133(4), 041701-041708.

Sipöcz, N. \& Tobiesen, F.A. (2012) Natural gas combined cycle power plants with CO2 capture - Opportunities to reduce cost. International Journal of Greenhouse Gas Control. 7, 98-106.

Spence, B., Horan, D. \& Tucker, O. (2014) The Peterhead-Goldeneye Gas Post-combustion CCS Project. Energy Procedia. 63, 6258-6266.

Tian, R., Zhang, Q. \& Wang, G. (2015) Market Analysis of Natural Gas Power Generation in China. Energy Procedia. 75, 2718-2723.

Turconi, R., O'Dwyer, C., Flynn, D. \& Astrup, T. (2014) Emissions from cycling of thermal power plants in electricity systems with high penetration of wind power: Life cycle assessment for Ireland. Applied Energy. 131, 1-8.

Wilcox, J. (2012) Carbon Capture. 1st edition. New York, Springer-Verlag. 